\title{
Selective modulation of cellular voltage-dependent calcium channels by hyperbaric pressure-a suggested HPNS partial mechanism
}

\author{
Ben Aviner $^{1 *}$, Gideon Gradwohl' ${ }^{2}$, Merav Mor Aviner ${ }^{1}$, Shiri Levy ${ }^{1}$ and Yoram Grossman ${ }^{1}$ \\ ${ }^{1}$ Department of Physiology and Neurobiology, Ben Gurion University of the Negev, Beer Sheva, Israel \\ 2 Department of Physics, Jerusalem College of Technology, Jerusalem, Israel
}

Edited by:

Egidio D'Angelo, University of Pavia,

Italy

Reviewed by:

Emilio Carbone, Department of Drug

Science, Italy

Jay B. Dean, University of South

Florida, USA

\section{*Correspondence:}

Ben Aviner, Department of

Physiology and Neurobiology, Ben

Gurion University of the Negev,

Building M6, Beer Sheva 84105 ,

Israel

e-mail: aviner@bgu.ac.il
Professional deep sea divers experience motor and cognitive impairment, known as High Pressure Neurological Syndrome (HPNS), when exposed to pressures of $100 \mathrm{msw}$ $(1.1 \mathrm{MPa})$ and above, considered to be the result of synaptic transmission alteration. Previous studies have indicated modulation of presynaptic $\mathrm{Ca}^{2+}$ currents at high pressure. We directly measured for the first time pressure effects on the currents of voltage dependent $\mathrm{Ca}^{2+}$ channels (VDCCs) expressed in Xenopus oocytes. Pressure selectivity augmented the current in Cav1.2 and depressed it in Cav3.2 channels. Pressure application also affected the channels' kinetics, such as TRise, TDecay. Pressure modulation of VDCCs seems to play an important role in generation of HPNS signs and symptoms.

Keywords: high pressure neurological syndrome, hyperbaric helium pressure, high pressure, voltage dependent calcium channels, synaptic transmission, conformational change, voltage dependency

\section{INTRODUCTION HPNS}

Every chemical reaction contributing to the continued existence of an organism is a potential target for pressure effects on biological processes. The major neurological problems associated with hyperbaric environments include $\mathrm{N}_{2}$ narcosis (inert-gas narcosis); $\mathrm{O}_{2}$ toxicity, which occurs due to increased oxidative stress (Allen et al., 2009); and HPNS (Halsey, 1982; Talpalar and Grossman, 2006). By controlling partial-pressures of absorbed tissue gases while under pressure, these neurological problems, excluding HPNS, can be alleviated and even eliminated, leading to the notion that HPNS occurs due to effects of pressure per se (Abraini, 1997; Bennett, 1997). Deep sea divers (approximately $>100 \mathrm{~m}$ ), as well as animals exposed to hyperbaric pressure (HP), may experience HPNS, which in humans includes dizziness, nausea, tremors, vision, and auditory disturbances, decrements in locomotor activity (Tarasiuk and Grossman, 1990; Darbin et al., 2000) and intellectual performance (Logue et al., 1986; Vaernes et al., 1988; Overman et al., 1989; Abraini, 1997; Steevens et al., 1999), confusion, changes in EEG and sleep disorders (Rostain et al., 1997), myoclonus (Darbin et al., 2000), convulsions, and loss of consciousness.

\section{Synaptic transmission}

Changes in synaptic transmission properties is a possible explanation for this constellation of signs and symptoms (for review see Daniels and Grossman, 2003). Indeed, it has previously been shown that synaptic transmission is suppressed by HP whether in vertebrate CNS synapse (Parmentier et al., 1981; SchleifsteinAttias et al., 1994), squid giant synapse (Parmentier et al., 1981), or crustacean neuromuscular junction (NMJ) (Campenot, 1975; Grossman and Kendig, 1990), either in excitatory (Grossman and Kendig, 1988; Golan et al., 1994) or inhibitory (Golan et al.,
1994) synapses. Postsynaptic reduction in receptor sensitivity, observed in glycine receptors (Shelton et al., 1993), will exacerbate pressure-induced suppression in specific synapses (Daniels and Grossman, 2003). Various mechanisms for HP effects on synaptic transmission have been suggested over the past few decades, including modulation of ionotropic receptors activity (Heinemann et al., 1987; Shelton et al., 1993), decreased action potential (AP) amplitude (Aviner et al., 2013) and slowed kinetics (Grossman and Kendig, 1986; Etzion and Grossman, 1999), generally observed depression of neurotransmitter release (Parmentier et al., 1981; Ashford et al., 1982; Gilman et al., 1987; Etzion et al., 2008), decreased vesicle fusion (Ashford et al., 1982; Heinemann et al., 1987), and the reduction of $\mathrm{Ca}^{2+}$ currents (Talpalar and Grossman, 2003; Aviner et al., 2013). HP also causes a decrease in the frequency of spontaneous miniature excitatory postsynaptic potentials (Ashford et al., 1982), which may also suggest that $\left[\mathrm{Ca}^{2+}\right]_{\mathrm{i}}$ could be involved in manifesting these HP effects. Indeed, it was also found that HP mimics the effects of low $\left[\mathrm{Ca}^{2+}\right]_{\mathrm{o}}$ (Grossman and Kendig, 1990; Etzion et al., 2008), and in contrast, high $\left[\mathrm{Ca}^{2+}\right]_{\mathrm{o}}$ can antagonize HP effects (Golan and Grossman, 1992; Talpalar et al., 2010; Aviner et al., 2013). Taken together, we may postulate that one of the major mechanisms by which HP suppresses synaptic transmission is a depression of $\mathrm{Ca}^{2+}$ influx into the presynaptic terminal through voltagedependent $\mathrm{Ca}^{2+}$ channels (VDCC), which is the natural trigger of this process. Indeed, Grossman and his colleagues have presented indirect (Grossman and Kendig, 1990; Grossman et al., 1991; Etzion and Grossman, 2000) and semi-direct (Aviner et al., 2013) evidence for this $\mathrm{HP}$ effect on voltage-dependent $\mathrm{Ca}^{2+}$ currents.

\section{Pressure- and voltage-dependent $\mathrm{Ca}^{2+}$ channels}

Various VDCC types exist, characterized by their electrophysiological and pharmacological traits (Cav1.1-4, 
$\mathrm{Ca}_{V}$ 2.1-3, Cav 3.1-3) and comprising the $\alpha_{1}, \alpha_{2} \delta, \beta$, and $\gamma$ subunits (Meir et al., 1999; Catterall, 2000). The major difference between the channels results from the variation in the $\alpha_{1}$ subunit, which holds the ion conducting pore, the voltage sensor, the channel gating section, and the known sites of channel regulation by second messengers, drugs, and toxins (Ertel et al., 2000). Evidence has accumulated, mostly indirectly, for HP effects on VDCC (Aviner et al., 2010). Pressure inhibited the brief reversal of swimming direction in the Paramecium, suggesting that an unclassified $\mathrm{Ca}^{2+}$ current that is associated with the reflex is impaired (Otter and Salmon, 1985). Depolarization-dependent $\mathrm{Ca}^{2+}$ influx into rat brain synaptosomes was depressed by pressure (Gilman et al., 1986). Membrane retrieval, another $\mathrm{Ca}^{2+}$-dependent process (Vogel et al., 1999; Wu et al., 2009), was also inhibited by pressure (Heidelberger et al., 2002).

Analysis of studies on crustacean neuromuscular synapses that examined the relationship between $\left[\mathrm{Ca}^{2+}\right]_{0}$, EPSC amplitude, and facilitation (Grossman and Kendig, 1988, 1990; Golan and Grossman, 1992) suggests that pressure is acting to reduce $\mathrm{Ca}^{2+}$ influx, rather than to affect intracellular removal of $\mathrm{Ca}^{2+}$ or the release process.

To date, no attempt was made to directly measure isolated $\mathrm{Ca}^{2+}$ currents at pressure. The work detailed in this manuscript aims to do so for the first time.

Alteration in the properties of these channels at pressure can significantly influence one's cognition, sensual perception, and ability to control posture and muscle activity in a manifestation that could depict the HPNS.

\section{METHODS \\ OOCYTES EXTRACTION AND cRNA INJECTION}

Oocytes of a Xenopus laevis mature female frog were surgically extracted from its ovary and treated with $1.5 \mathrm{mg} / \mathrm{ml}$ collagenase for 30-60 min in order to remove connecting tissue. Suitable oocytes were sorted out by size, quality, and developmental stage (VI), and kept in NDE96 solution containing (in mM): $96 \mathrm{NaCl}$, $2 \mathrm{KCl}, 1 \mathrm{MgCl}_{2}, 1 \mathrm{CaCl}_{2}, 2.5$ sodium pyruvate; $50 \mu \mathrm{g} / \mathrm{ml}$ gentamycin; 5 HEPES pH 7.5.

cRNAs of the subunits of L or T type $\mathrm{Ca}^{2+}$ channels (LTCC or TTCC, respectively) were synthesized from rabbit cDNA by in vitro transcription with T7 or SP6 Amplicap High-Yield Message Maker Kit (Epicentre Technologies, Madison, WI). Oocytes were then injected with the specific cRNA mix $(2.5 \mathrm{ng})$ encoding for the pertinent subunits to express LTCC or TTCC and were kept in an incubator for 4 days at $18^{\circ} \mathrm{C}$ in NDE96 solution. The following subunits were used: $\alpha_{1 \mathrm{C}}+\beta_{2 \mathrm{~A}}+\alpha_{2} \delta$, comprising the LTCC Ca 1.2 ; and $\alpha_{1 \mathrm{H}}+\alpha_{2} \delta$, comprising the TTCC Cav3.2, whose gene code numbers are $\alpha_{2} \delta-\mathrm{M} 21948$, $\beta_{2}-\mathrm{X} 64297, \alpha_{1 \mathrm{C}}-\mathrm{X} 15539$, and $\alpha_{1 \mathrm{H}}-\mathrm{AF} 051946$.

\section{ELECTROPHYSIOLOGICAL RECORDINGS}

Four days post-injection the oocytes were placed in a specially designed bath, and two-electrode voltage clamp (TEVC) experiments with $10 \mathrm{mV}$ increments and 5-10 s interval between -70 and $40 \mathrm{mV}$ were performed inside a compression chamber, utilizing an AXOCLAMP 2B amplifier (Molecular Devices, Axon Instruments, Inc., CA, USA), Master-8-cp Pulse Generator
(A.M.P.I.), and AxoScope 9.2 software. While in the chamber, each oocyte was continuously perfused with a $\mathrm{Ba}^{2+}$ solution containing (in $\mathrm{mM}$ ): $40 \mathrm{Ba}(\mathrm{OH})_{2}, 50 \mathrm{NaOH}, 2 \mathrm{KOH}$, and 5 HEPES, titrated to $\mathrm{pH} 7.5$ with methanesulfonic acid. $\mathrm{Ba}^{2+}$ was used as charge carrier, replacing the $\mathrm{Ca}^{2+}$ ions, in order to avoid $\mathrm{Ca}^{2+}$. dependent inactivation and the activation of $\mathrm{Ca}^{2+}$-activated $\mathrm{Cl}^{-}$ channels $\left(\mathrm{Cl}_{\mathrm{Ca}}^{-}\right)$, known to be endogenously expressed in oocyte membrane (Miledi and Parker, 1984). The channels also have higher conductance to $\mathrm{Ba}^{2+}$ (Tsien et al., 1987), allowing measurement of minute currents that otherwise would have been unnoticed. The solution, saturated with air at atmospheric pressure, was introduced to the chamber by the use of a high pressure pump (Minipump, LDC Analytical Inc., Riviera Beach, FL, USA) at room temperature $\left(24-25^{\circ} \mathrm{C}\right)$, at a rate of $1.5-2 \mathrm{ml} / \mathrm{min}$. Temperature was constantly monitored throughout the experiments by the use of a thermistor submerged in the solution in the vicinity of the oocyte groove. Deviation of only $\pm 0.5^{\circ} \mathrm{C}$ was allowed from the control temperature for later measurements.

Typical recording traces are shown in Figures 1A-D. For the oocytes expressing $\mathrm{Ca}_{\mathrm{V}} 1.2$, holding potential was $-70 \mathrm{mV}$ (Figure 1A). The duration of each depolarizing step was $500 \mathrm{~ms}$, which was preconditioned by a $100 \mathrm{~ms}$ hyperpolarizing step

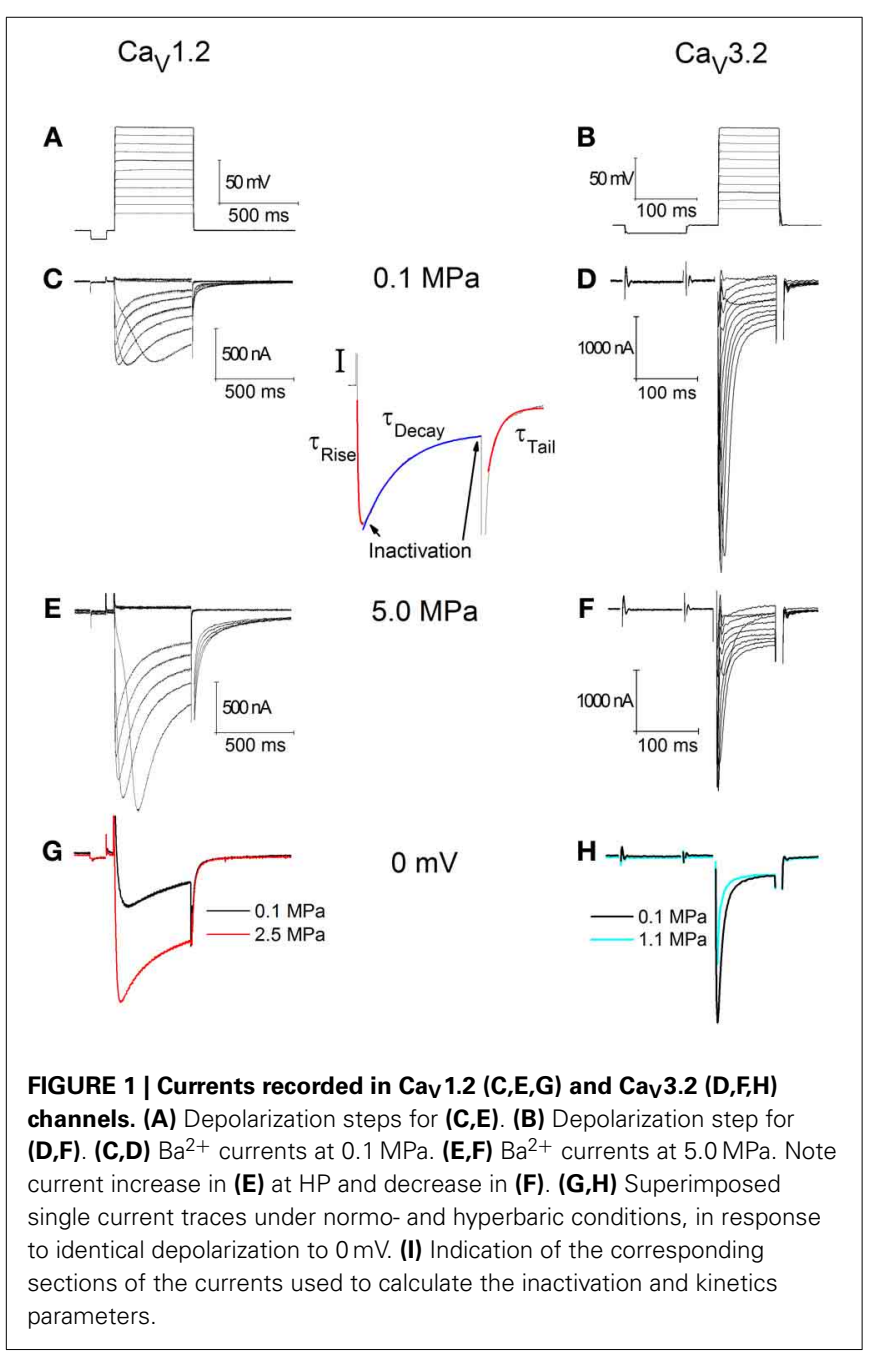


to $-80 \mathrm{mV}$ in order to release the VDCC from partial inactivation. The latter was also used to calculate and monitor the oocytes' instantaneous input resistance, which was accounted for at each recorded trace separately. For the oocytes expressing $\mathrm{Ca}_{\mathrm{V}} 3.2$ holding potential was $-80 \mathrm{mV}$ (Figure 1B). The duration of each depolarizing step was $100 \mathrm{~ms}$, preconditioned by a $150 \mathrm{~ms}$ hyperpolarizing step to $-90 \mathrm{mV}$, for similar reasons.

Every series of depolarizing pulses was used to construct an I-V curve and repeated at least three times in order to verify stability of the currents. Recorded traces with voltage fluctuation greater than $2 \mathrm{mV}$ during depolarization were disregarded. We studied HP effects (examples in Figures 1C,D) on I-V curve, maximal currents, activation and inactivation functions, channel kinetics such as time to peak and time constants $(\mathrm{T})$, and voltage dependency. Maximal currents were measured at the minimal point of the current curve (Figure 1I, left arrow). Inactivation $\left(\mathrm{I} / \mathrm{I}_{\max }\right)$ was measured toward the end of the depolarizing step (Figure 1I, right arrow) in comparison to the measured maximal current (as above). A fit was calculated for each decaying section of the current in every recorded trace (Figure 1I, blue fit) according to a biexponential equation defining two time constants for decay:

$$
\text { Fit }=-\mathrm{A} 1 \exp \left(-t / \tau_{\text {Decay Fast }}\right)-\mathrm{A} 2 \exp \left(-t / \tau_{\text {Decay Slow }}\right)+\mathrm{C} .
$$

For the rising phase and the tail currents a single exponential fit was performed (Figure 1I, red fits). All fits were calculated between the curves' normalized values of 0.1 and 0.9 .

Activation volume $\left(\Delta \mathrm{V}^{\ddagger}\right)$ was calculated for time constants of channel activation, inactivation, and deactivation under normobaric and hyperbaric conditions, following the known equation: $\Delta \mathrm{V}^{\ddagger}=\mathrm{RT}(\partial \ln \mathrm{T} / \mathrm{\partial P})_{\mathrm{T}}$.

\section{TRUNCATED $\boldsymbol{K}^{+}$CHANNEL}

The current measurement using TEVC method was carried out for long durations and under HP conditions. Since it was our first attempt, verification of the recording stability was needed. As a first approximation, a truncated variant of a Drosophila $\mathrm{K}^{+}$channel (KCNKØ) missing its carboxy-terminal tail (700 residues) was injected into oocytes $(n=4)$, causing a shift of their normal resting potential from about -40 to $-50 \mathrm{mV}$ to approximately $-80 \mathrm{mV}$ (Zilberberg et al., 2000). The membrane potential of these oocytes was then measured for $1-2 \mathrm{~h}$ and demonstrated stable resting potential of $-80 \pm 2 \mathrm{mV}$ (not shown). This result showed that the setup measurements are accurate and do not drift throughout the duration of the experiment.

\section{$\mathrm{Ca}^{2+}$-ACTIVATED $\mathrm{Cl}^{-}$CHANNEL BLOCKER}

In an attempt to clarify whether $\mathrm{Ba}^{2+}$ currents measured in the VDCCs over-expressed in the oocyte membrane are subjected to artifacts caused by currents via endogenous channels, we performed a series of experiments in $\mathrm{Ca}_{\mathrm{V}} 1.2$ channels using 9Anthracene carboxylic acid (9-AC), a pharmacological blocker of the $\mathrm{Cl}_{\mathrm{Ca}}^{-}$(Boton et al., 1989). The use of $\mathrm{Ca}^{2+}$ chelators, e.g., BAPTA or EGTA, was not feasible due to their short timespan effectiveness in relation to the duration of our experiments (see Results, Time stability of HP effect). 9-AC was dissolved at $0.2-0.5 \mathrm{M}$ in a $1 \mathrm{M}$ solution of $\mathrm{NaOH}$. This stock solution was then added to the physiological measurement solution to a final 2-4 mM concentration (Boton et al., 1989). Titration to $\mathrm{pH} 7.5$ was then done using Methanesulfonic acid.

\section{HELIUM COMPRESSION}

After control measurement taken at $0.1 \mathrm{MPa}$, compression steps to $0.5,1.0,2.5$, and $5.0 \mathrm{MPa}$ were performed by compressed helium. Since the cDNA used to express these channels was of rodent origion, which is generally more resistant to HP than human, compressions greater than 1.0 MPa were also performed. Compression was done manually from a tank through a set of valves into the pressure chamber. Compression rate was approximately $0.25-0.5 \mathrm{MPa} / \mathrm{min}$, and never exceeded $1.0 \mathrm{MPa} / \mathrm{min}$. Helium was used instead of air due to its inert quality and the need to avoid known nitrogen narcosis and oxygen toxicity related effects (Dean et al.,, 2003). All pressure units are absolute.

\section{STATISTICAL ANALYSIS}

The full set of parameters was calculated off-line for each recorded trace separately, considering the instantaneous input resistance and leak currents where appropriate, using a dedicated selfdesigned Matlab software program. The data were exported to Microsoft Excel software, by which averaging and binning were performed. Each oocyte was used as its own control, thus values were normalized to $0.1 \mathrm{MPa}$. When data from more than one oocyte were pooled, binning was performed relative to the voltage generating the maximal current in the I-V curve $\left(\mathrm{V}_{\text {Imax }}\right)$; hence in figures representing these data (Figures 2 to $9 \mathrm{C}-\mathrm{F}$ ) the $\mathrm{X}$-axis title is $\Delta \mathrm{V}$. Paired sample $t$-test was used to analyze the significance of the results.

\section{RESULTS}

\section{INCREASED CURRENT IN Cav1.2}

Generally, HP was expected to suppress currents of VDCCs (see Introduction). Surprisingly, $\mathrm{Ba}^{2+}$ currents in $\mathrm{Ca}_{\mathrm{V}} 1.2$ were significantly increased in oocytes exposed to HP (0.5-5.0 MPa, see example in Figures 1E,G and 2A) in a dose-dependent manner, throughout the channels' voltage range of activity. Compression to $0.5,2.5$, and $5.0 \mathrm{MPa}$ augmented the maximal currents by 28 $\pm 10,58 \pm 22$, and $70 \pm 32 \%$, respectively (Figure 2C, Average \pm SEM, $p<0.01, n=9-17)$. Decompression back to $0.1 \mathrm{MPa}$ only partially reversed the HP effect, leaving the maximal current $44 \pm 19 \%$ increased. Neither the threshold voltage nor the depolarization $\left(\mathrm{V}_{\text {Imax }}\right)$ that generated the largest currents (negative peak in IV curve) was affected.

Normalizing each IV curve under the various pressures to its own maximal (negative) peak (Figure 2E) shows almost identical curves, and therefore suggests that the channel's sensitivity to the membrane voltage did not alter as a result of the compression.

\section{ADIABATIC TEMPERATURE CHANGE AND TIME STABILITY}

Elevation of ambient pressure in these experiments was achieved by gaseous (helium) compression; hence an adiabatic temperature rise always occurred (typically $0.5-2^{\circ} \mathrm{C}$, but never more than $4^{\circ} \mathrm{C}$ ), which was controlled by the rate of compression. 

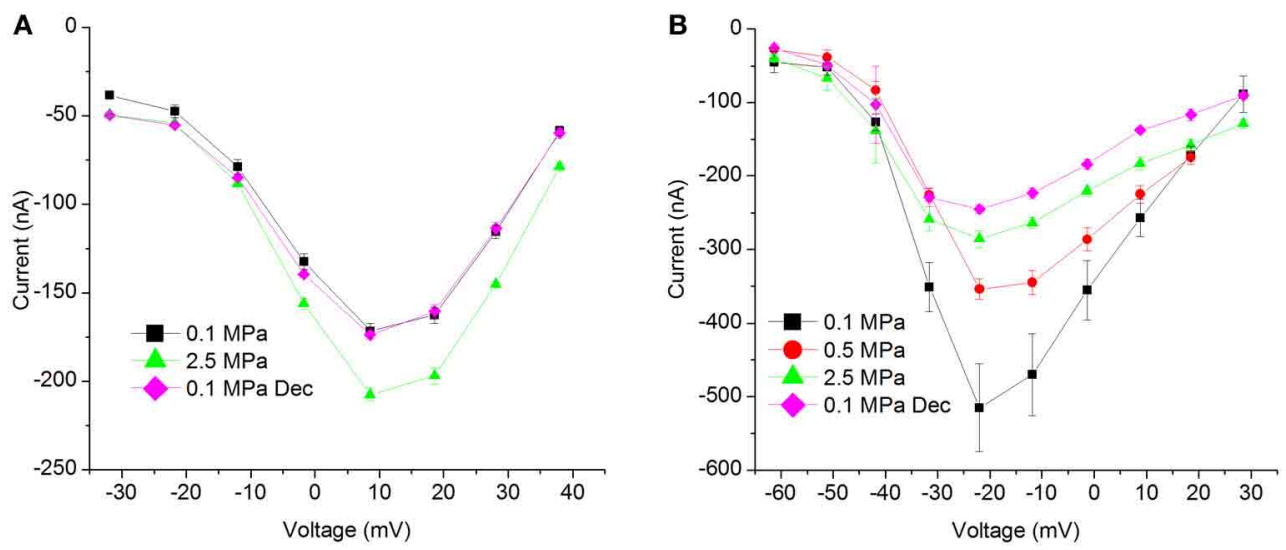

C

D

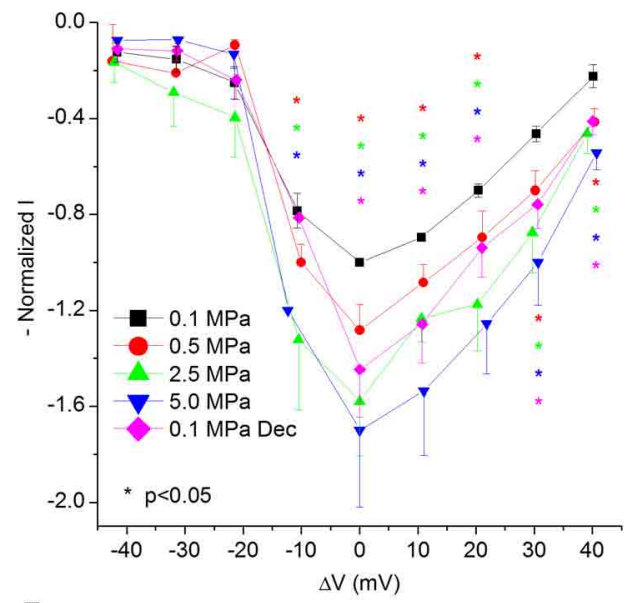

E
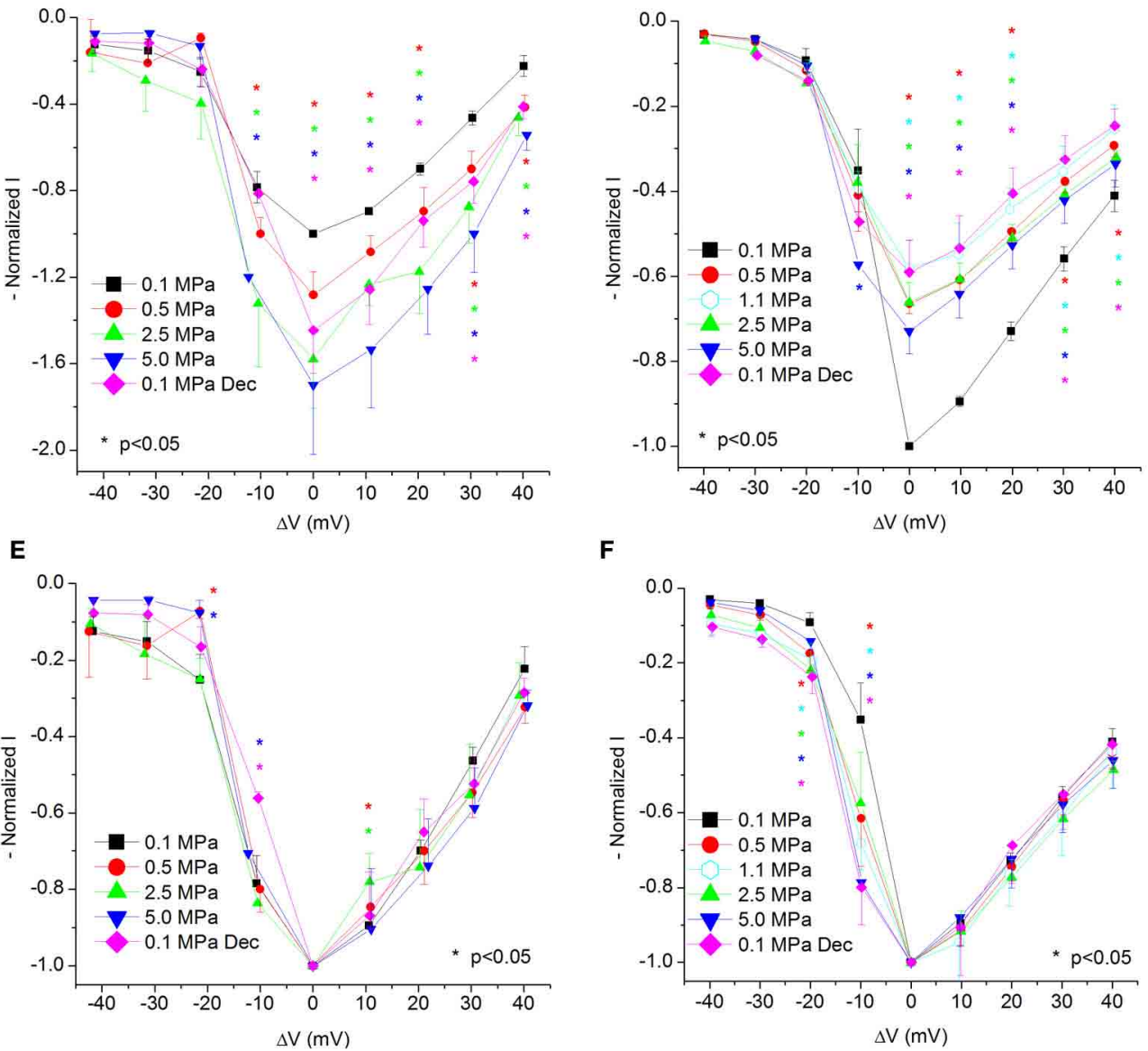

$\mathbf{F}$

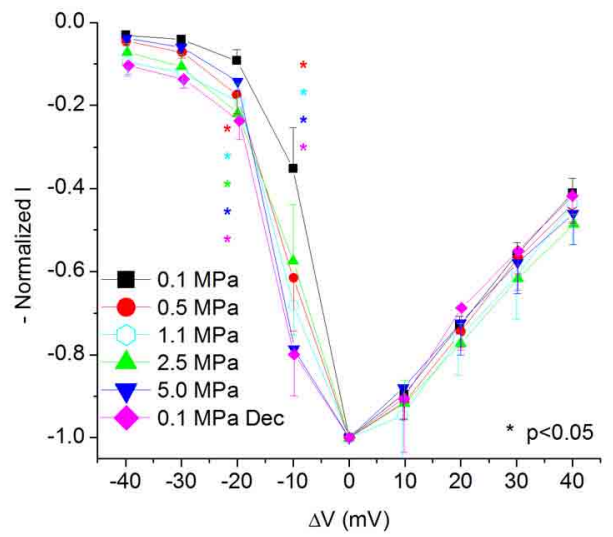

FIGURE 2 | I-V curves of maximal currents. (A,C,E) Cav1.2, (B,D,F) Cav3.2 channels. (A,B) I-V curve of a single oocyte. (C,D) Pooled data from 9 to 17 (C) and 7 to 9 (D) oocytes exposed to $0.5-5.0 \mathrm{MPa}$ pressure (color indicated). Holding potential is adjusted so that 0 indicates the potential at which maximal current is obtained $\left(V_{\text {Imax }}\right)$.

Only measurements within $0.5^{\circ} \mathrm{C}$ or less of control temperature were taken under consideration. Therefore, it was necessary to wait for the chamber's atmosphere (bath fluid) to cool down (lasting 10-30 min), resulting in 1-2 h long experiments. Figure $3 \mathrm{~A}$ shows IV curves in an oocyte expressing $\mathrm{Ca}_{V} 1.2$ recorded at 5.0 $\mathrm{MPa}$ (post-compression) while cooling back to control temperature $\left(24^{\circ} \mathrm{C}\right)$. As expected, elevated temperature (in addition to the HP) led to an increase in the currents. However, even after the control temperature was regained, the augmented current persisted. This strongly indicates that the 

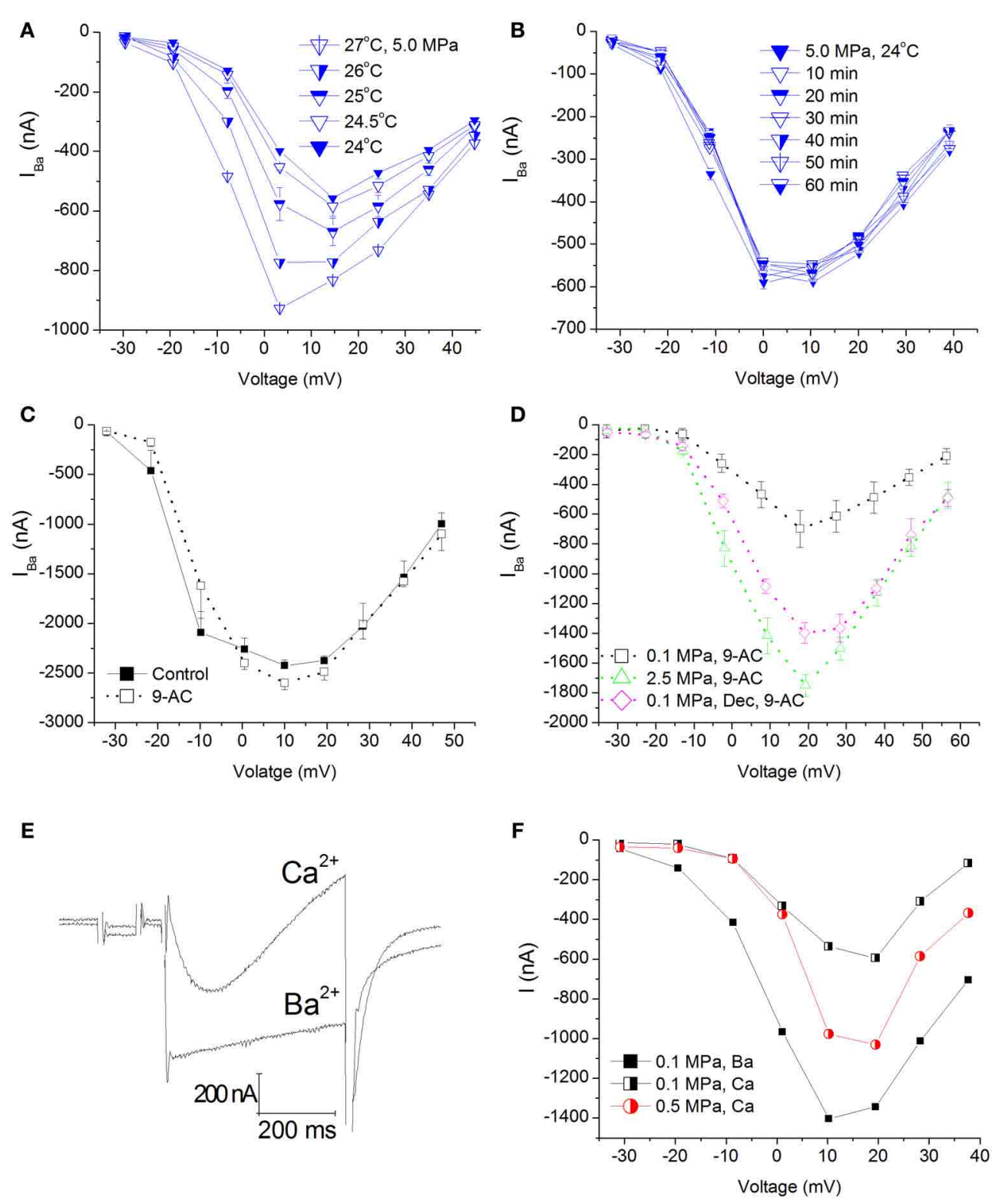

FIGURE 3 | Temperature, time, $\mathrm{Cl}_{\mathrm{Ca}}^{-}$channel blocker, and $\mathrm{Ca}^{2+}$ ion control experiments in $\mathrm{Ca}_{V} \mathbf{1 . 2}$ channel. (A) $I-V$ curves measured at 5.0 MPa repeatedly while the preparation's adiabatic temperature change is subsiding. (B) I-V curves measured in a different oocyte for $1 \mathrm{~h}$ at $5.0 \mathrm{MPa}$ after control temperature was regained. (C) $\mathrm{I}-\mathrm{V}$ curves measured in a solution containing 9-AC. (D) I-V curves of compression and decompression performed with 9-AC. The expected HP effect

temperature fluctuation cannot solely explain the increase in the channel's current and it should reflect a direct effect of HP (as also shown in Figure 2A). In order to verify that, and to rule out the possibility that the surprising augmentation of Cav1.2 current at pressure is only the result of the adiabatic temperature change or a transient HP effect, currents were measured for $1-2 \mathrm{~h}$ post-compression (different experiments $n=2$, Figure 3B). As can be seen, currents remained stable at HP for long durations after cooling back to control temperature, thus (augmentation) is evident. (E) Example of current traces recorded with $\mathrm{Ca}^{2+}$ or $\mathrm{Ba}^{2+}$ ions in the solution at the same depolarization to $0 \mathrm{mV}$. Note the stronger and faster inactivation with $\mathrm{Ca}^{2+}$. (F) Compression to $0.5 \mathrm{MPa}$ when $\mathrm{Ba}^{2+}$ ions were replaced by $\mathrm{Ca}^{2+}$ ions. Replacement of ions caused a decrease of the currents at $0.1 \mathrm{MPa}$, but compression to $0.5 \mathrm{MPa}$ still augmented the $\mathrm{Ca}^{2+}$ current in a similar manner to $\mathrm{Ba}^{2+}$ experiments. 
to avoid any current flowing through these channels in the unlikely event of their activation, the solution was also $\mathrm{Cl}^{-}$free. Performing a TEVC experiment on naïve oocytes generated maximal currents in the 10-30 nA range (not shown), considered negligible compared to $1000 \mathrm{nA}$ and more measured in oocytes expressing the Cav1.2 channel. Nevertheless, we performed two sets of experiments aimed to verify that the theoretical $\mathrm{Cl}_{\mathrm{Ca}}^{-}$ current does not play a role in the HP-related effect, by adding 9-AC (a Ca ${ }^{2+}$-activated $\mathrm{Cl}^{-}$channel blocker, see Methods) to the solution before or after compression (Figure 3C). Neither adding 9-AC pre-compression (Figure 3D) nor 9-AC added postcompression altered the HP-induced augmentation of $\mathrm{Ca}_{V} 1.2$ current, indicating that the HP effect is real.

\section{$\mathrm{Ba}^{2+}-\mathrm{Ca}^{2+}$ SUBSTITUTION}

Since $\mathrm{Ca}^{2+}$ was substituted for $\mathrm{Ba}^{2+}$ due to the reasons mention in Methods, we wanted to verify that the HP effect is still valid when using the native $\mathrm{Ca}^{2+}$ ion. As expected, changing the bath solution to contain $\mathrm{Ca}^{2+}$ (using the $\mathrm{Ca}_{V} 1.2$ channel) resulted in a decrease in the measured current and a faster and stronger inactivation (Figures 3E,F, black curves). Application of pressure augmented this current as well (Figure 3F, red curve).

\section{DECREASED CURRENT IN Cav3.2}

$\mathrm{Ba}^{+}$currents in Cav3.2 were significantly decreased at HP $(0.5-5.0 \mathrm{MPa})$ in a dose-dependent manner (see example in Figures $\mathbf{1 F}, \mathbf{H}$ and $\mathbf{2 B}$ ), in contrast to the findings of $\mathrm{Ca}_{\mathrm{V}} 1.2$. Preliminary results showed that the HP effect did not change between 2.5 and 5.0 MPa; therefore another pressure step to 1.1 MPa was added in subsequent experiments in order to reveal the HP effect saturation. Neither the threshold voltage nor the $\mathrm{V}_{\text {Imax }}$ were affected. Compression to $0.5,1.1,2.5$, and $5.0 \mathrm{MPa}$ depressed the maximal currents by $33 \pm 2,42 \pm 6,34 \pm 5$, and $27 \pm 5 \%$, respectively (Figure 2D, Average \pm SEM, $p<0.01$, $n=4-9)$. Decompression to $0.1 \mathrm{MPa}$ failed to recover the current, which remained depressed by $40 \pm 7 \%$. Normalizing each IV curve under the various pressure conditions to its own maximal (negative) peak (Figure 2F) reveals an increase of the currents in $\mathrm{Ca}_{\mathrm{V}} 3.2$ at sub-maximal membrane potentials $(\Delta \mathrm{V}-10 \mathrm{mV})$, but not at $\mathrm{V}_{\text {Imax }}$ and above. We hypothesize that this might occur due to a greater probability for transition to the open state of the channel in this voltage range.

\section{CHANNEL CONDUCTANCE}

Calculating the channel conductance in relation to the membrane potential shows similar results to the general findings in the IV curves (see examples in Figures 4A,B). HP decreased the conductance in the $\mathrm{Ca}_{V} 3.2$ channel (Figure 4D) and increased it in the Cav1.2 channel (Figure 4C). On average, the change from threshold to maximal normalized response occurred within a $20 \mathrm{mV}$ depolarization range for the Cav3.2 channel and $30 \mathrm{mV}$ for the $\mathrm{Ca}_{\mathrm{V}} 1.2$ channel. Normalizing each curve to its own maximal value (Figures 4E,F) reveals in the $\mathrm{Ca}_{V} 3.2$ channel the same tendency seen in the normalized IV curve (Figure 2F) for greater conductance at $\mathrm{HP}$ in the $\Delta \mathrm{V}-10 \mathrm{mV}$ membrane potential, whereas the $\mathrm{Ca}_{\mathrm{V}} 1.2$ channel did not show such trait (Figure 4E). For depolarizations above $\mathrm{V}_{\text {Imax }}$ only compression to $0.5 \mathrm{MPa}$ caused a consistent small reduction in normalized conductance in both channels.

\section{CURRENT INACTIVATION}

The significant effect of HP on these channels manifested in the current and conductance parameters has led us to ask why pressure changes the total flux through them during supra-threshold depolarizations. A possible explanation could be that the channels' kinetics is affected by pressure. Previous findings have correlated HP to slowed inactivation in $\mathrm{Na}^{+}$channels (Henderson and Gilbert, 1975; Conti et al., 1982b) and compared the effect of higher pressure to lower temperature (Grossman and Kendig, 1984, 1986). We therefore tested a few of the channels' kinetic properties. We first examined channel inactivation, measured as the ratio between the remaining fraction of the current at the end of the depolarizing voltage step and its maximal value $\left(\mathrm{I}_{\text {end }} / \mathrm{I}_{\text {max }}\right.$; see examples in Figures 5A,B). The lack of $\mathrm{Ca}^{2+}$ ions in the experimental solution has eliminated the $\mathrm{Ca}^{2+}$-dependent inactivation and most likely guaranteed that only the voltageand time-dependent inactivation will be measured. To verify this assumption, and in order to serve as a reference, a few experiments were conducted $(n=5)$ using a solution in which the $\mathrm{Ba}^{2+}$ was replaced with an equivalent concentration of $\mathrm{Ca}^{2+}$ (example in Figure 3E). As expected, in the presence of $\mathrm{Ca}^{2+}$ a stronger (2-fold) and faster (4-fold) inactivation was observed.

For the $\mathrm{Ca}_{\mathrm{V}} 1.2$ channel, inactivation was stronger at $\mathrm{V}_{\text {Imax }}$, but was weakened at stronger depolarizations $(\Delta \mathrm{V} 10-40 \mathrm{mV}$, Figure 5C). Decompression did not relieve the HP effect. For the $\mathrm{Ca}_{V} 3.2$ channel, the inactivation was stronger around the threshold voltage $(\Delta \mathrm{V}-20$ to $-10 \mathrm{mV})$ at $\mathrm{HP}$, but was weakened at $\mathrm{V}_{\text {Imax }}$ at lower HP (1.1 MPa).

Normalizing each curve to its own minimal value stresses the tendency for the strongest inactivation to occur in the Cav1.2 channel at $\mathrm{V}_{\mathrm{Imax}}$ at $\mathrm{HP}$, whereas at normobaric pressure and post-decompression it occurs at the strongest depolarization, as expected for this VDCC (Figure 5E). For the $\mathrm{Ca}_{V} 3.2$ channel, although the normalized curves converge at high depolarization, in most supra-threshold membrane potentials inactivation remained stronger at $\mathrm{HP}$ (Figure 5F).

\section{CURRENTS TIME TO PEAK}

If the rate of activation of the VDCCs is affected by HP, that may change the time window for the ionic flow through them before the voltage- and time-dependent inactivation takes place. In case activation is as slow as inactivation, that will affect the $I_{\max }$ in each depolarization. We have therefore measured the time passing from the stimulating depolarizing step to the development of $\mathrm{I}_{\max }$ (time to peak, TTP). Examples can be seen in Figures 6A,B.

For the Cav1.2 channel the TTP was increased at HP near $\mathrm{V}_{\text {Imax }}(\Delta \mathrm{V}-10$ to $10 \mathrm{mV}$, Figure $6 \mathrm{C})$. Decompression did not relieve this effect.

For the $\mathrm{Ca}_{\mathrm{V}} 3.2$ channel TTP was decreased in the range between of $\Delta \mathrm{V}-20$ to $0 \mathrm{mV}$ (Figure 6D). An increase of TTP was observed after decompression above $\mathrm{V}_{\text {Imax }}$.

Normalizing each TTP curve to its own minimal value (normally achieved at strong depolarization) showed the 

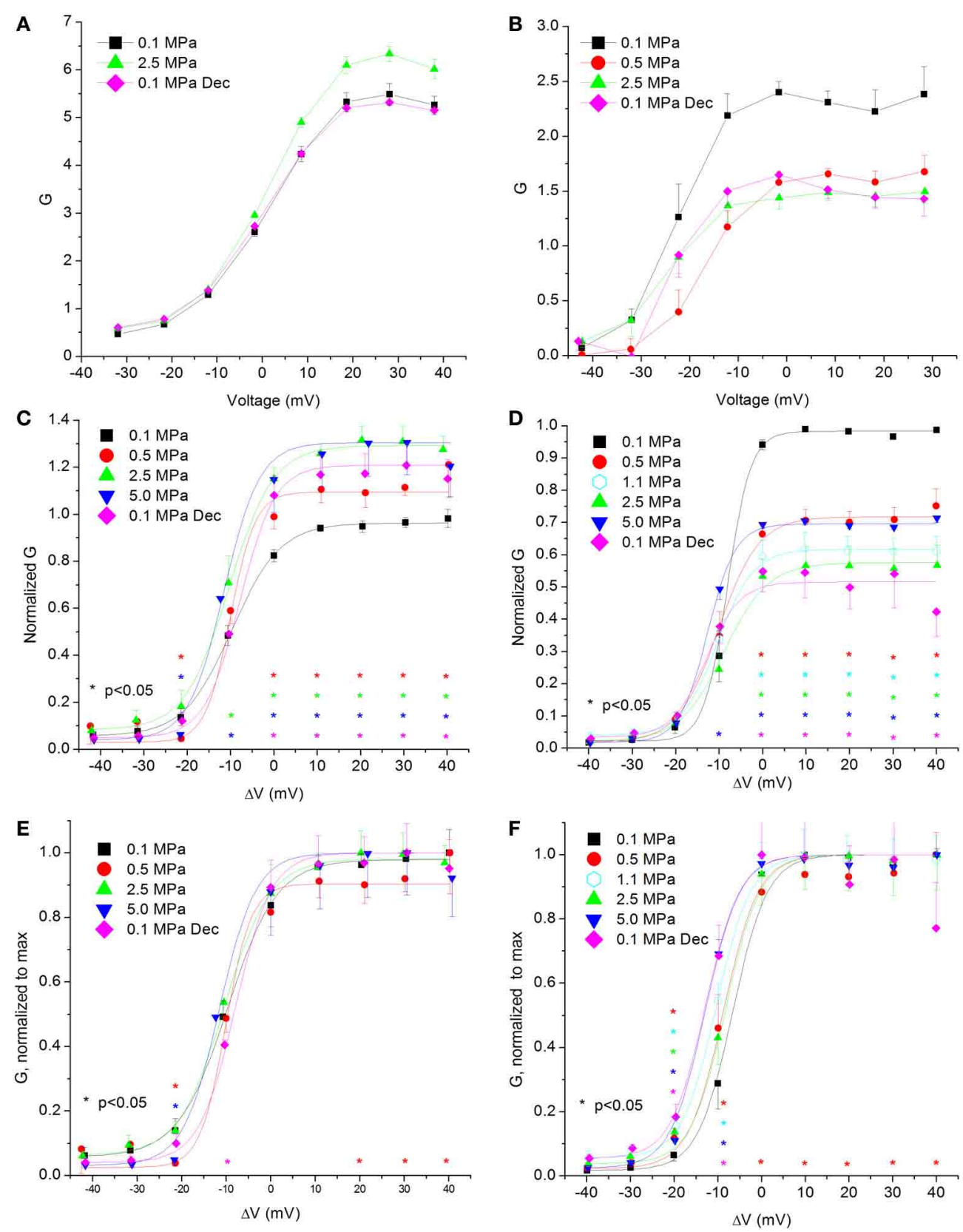

FIGURE 4 | Channels' conductance at various pressures. (A,C,E) In Cav1.2 and $(\mathbf{B}, \mathbf{D}, \mathbf{F})$ in Cav3.2 channels. $(\mathbf{A}, \mathbf{B})$ Conductance measured in a single oocyte. (C,D) Pooled data of the channels. (E,F) Normalized conductance: each curve is normalized to its own maximal value and corresponds to its

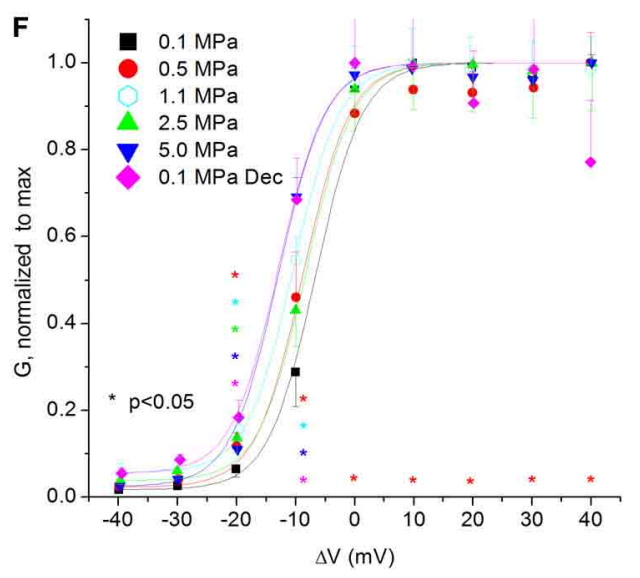

pertinent curve in (C,D). A Boltzmann fit was used in (C-F). Pressures are color indicated. Statistical significance for each point on the curve is indicated by corresponding color asterisks. Holding potential is expressed as in Figure 2. Dec indicates decompression.

same tendencies: an increased TTP in the Cav1.2 channel (Figure 6E) and a decreased TTP in the Cav3.2 channel (Figure 6F).

\section{CURRENTS TRISE}

A complementary trait for the TTP in regard to the opening of the channel is the time constant of the rising phase of the current, TRise. Slower TTP should mean greater TRise, and vice versa. Indeed, in the Cav1.2 HP caused an increase in the
TRise values at $\mathrm{V}_{\text {Imax }}$ and $10 \mathrm{mV}$ above (Figure 7A). Greater depolarizations led to convergence of $T_{\text {Rise }}$ to control values (Figure 7B). Decompression only partially recovered $T_{\text {Rise }}$, which remained elevated at $\mathrm{V}_{\text {Imax }}$. Normalizing each curve to its own minimal value demonstrates a similar rise in $T_{\text {Rise }}$ at $\mathrm{V}_{\text {Imax }}$ and $\Delta \mathrm{V} 10 \mathrm{mV}$ (Figure 7C), which might support the notion that HP interferes with the opening mechanism of this channel, i.e., slows its kinetics. $\Delta \mathrm{V}^{\ddagger}$ of current activation for $\mathrm{CaV}_{\mathrm{V}} 1.2$ at $\mathrm{V}_{\text {Imax }}$ was calculated to be $454 \mathrm{ml} / \mathrm{mole}$ at $5.0 \mathrm{MPa}$. 

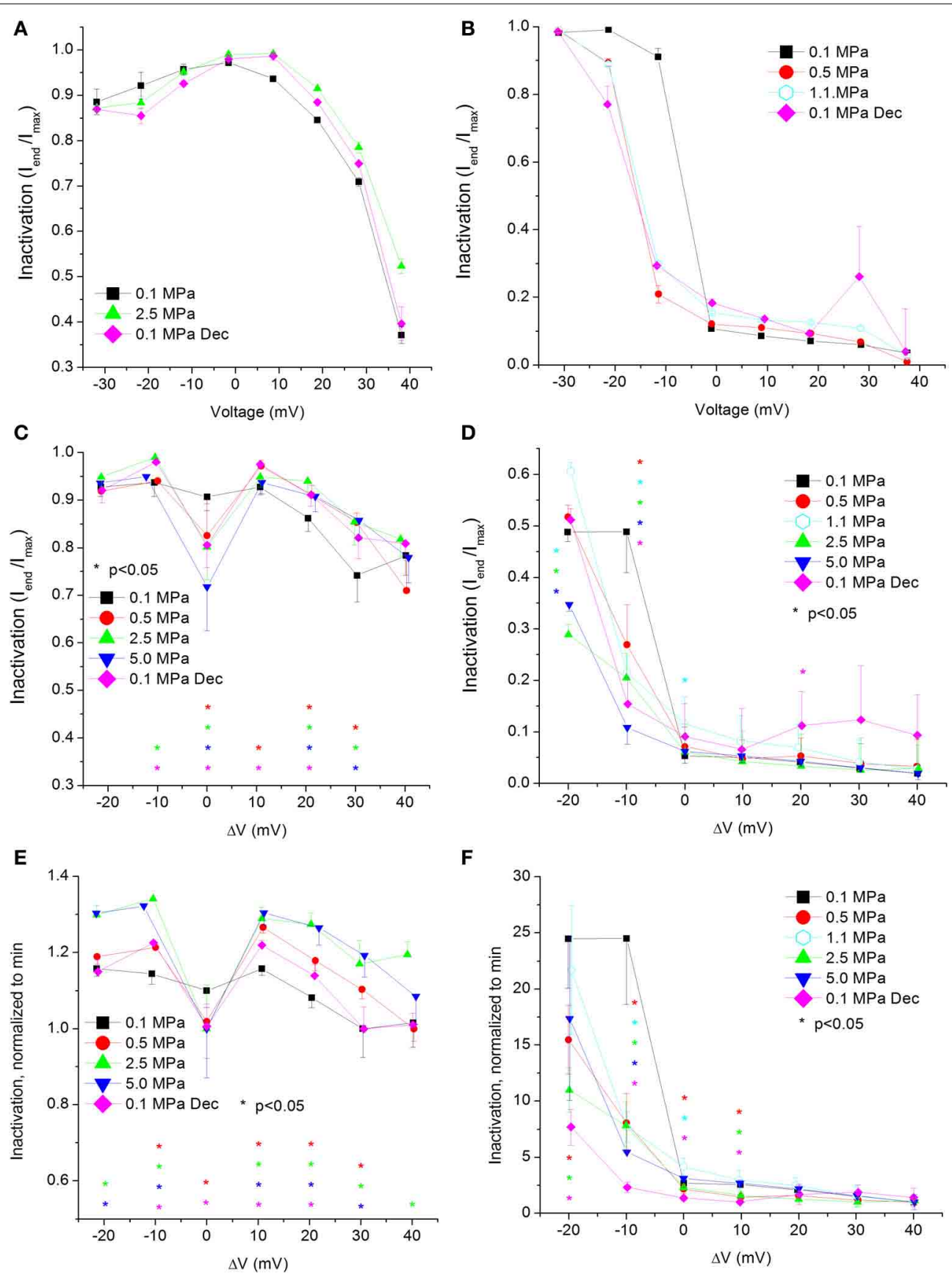

$\mathbf{F}$

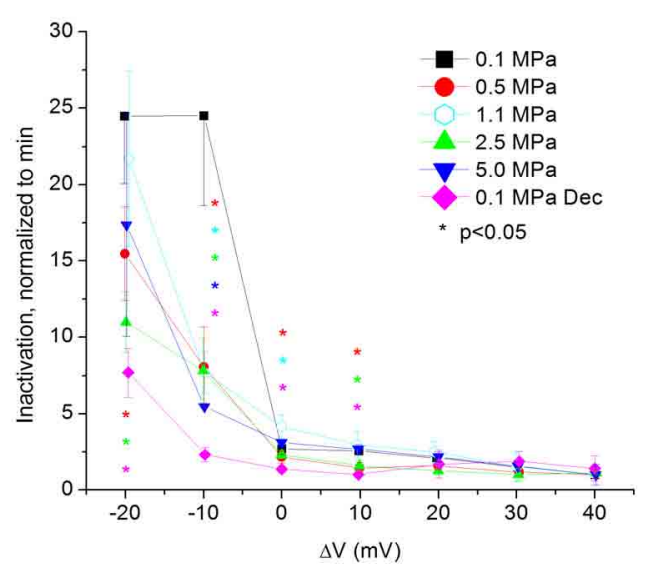

FIGURE 5 | Voltage- and time-dependent current inactivation $\left(I_{\text {end }} / I_{\max }\right)$ at various pressures. (A,C,E) In Cav1.2 and (B,D,F) in Cav3.2 channels. (A,B) Inactivation measured in a single oocyte. (C,D) Pooled data of the channels. $(\mathbf{E}, \mathbf{F})$ Normalized inactivation: each curve is normalized to its own minimal

value and corresponds to its pertinent curve in (C,D). Pressures are color indicated. Statistical significance for each point on the curve is indicated by corresponding color asterisks. Holding potential is expressed as in Figure 2. Dec indicates decompression.

Unfortunately, relatively large currents measured in the $\mathrm{Ca}_{\mathrm{V}} 3.2$ channel were accompanied by an artifact during their rising phase, which prevented accurate measurement of their $\mathrm{T}_{\text {Rise }}$.

\section{CURRENTS FAST TDECAY}

The changes in inactivation $\left(\mathrm{I}_{\mathrm{end}} / \mathrm{I}_{\max }\right)$ found in both channels at HP could arise from its effect on their rate of decay, since $I_{\text {end }}$ was measured here after a specific time and not under steady state conditions. The analysis revealed fast and slow time constants for the decay (see examples in Figures 8A,B, 9A,B), the first being shortened by stronger depolarizations and the latter being elongated.

For the $\mathrm{Ca}_{\mathrm{V}} 1.2$, HP caused a decrease in the fast TDecay ( Decay Fast $_{\text {) at }} \mathrm{V}_{\text {Imax }}$ and $10 \mathrm{mV}$ below (Figure 8C). Stronger 

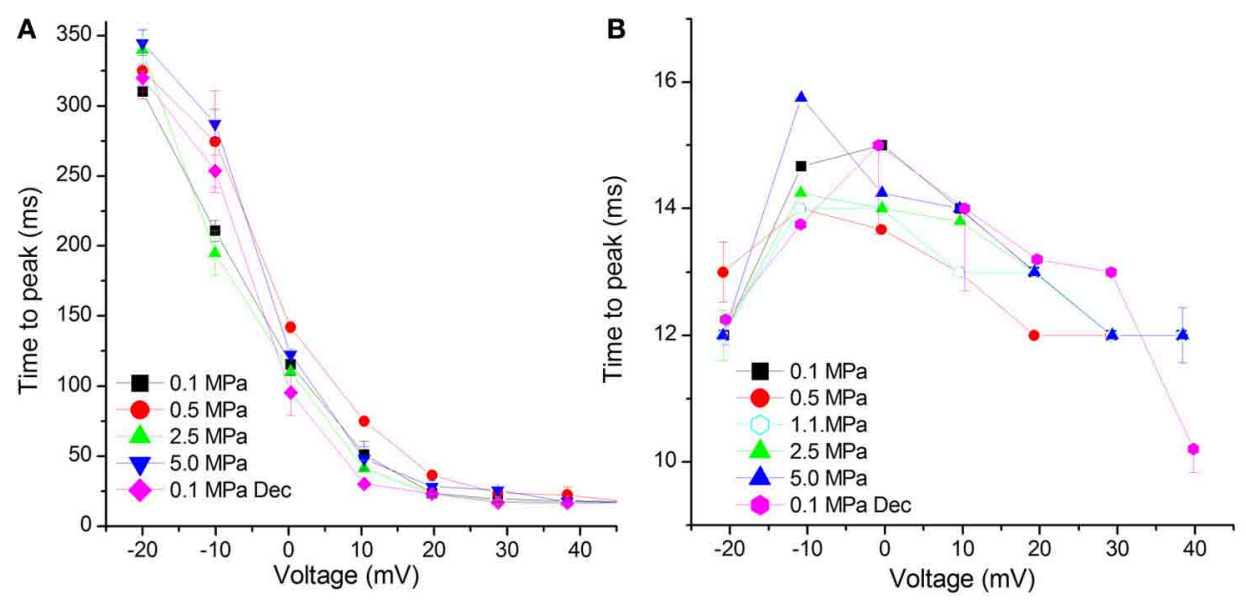

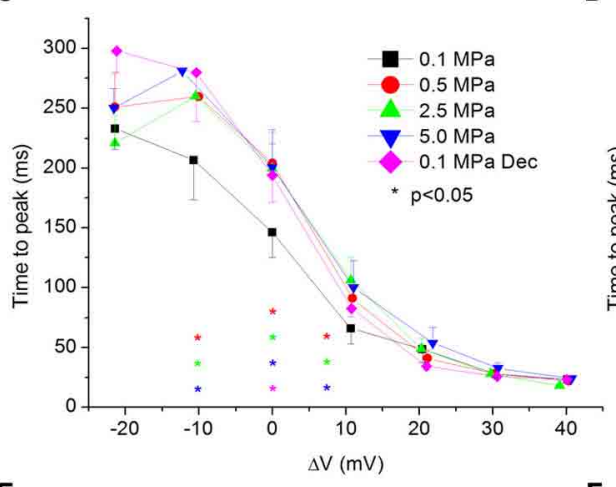

$\mathbf{E}$

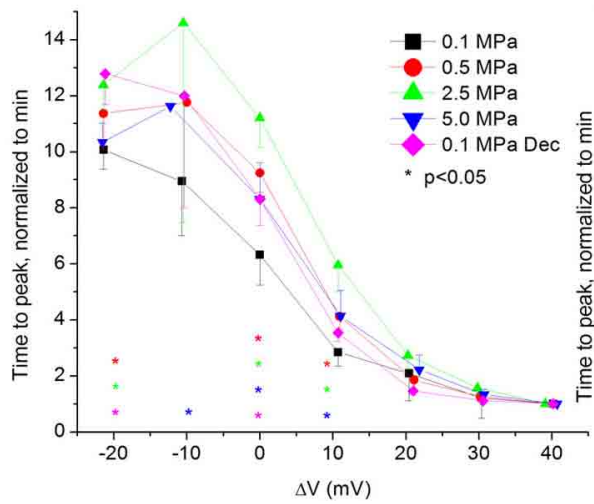

FIGURE 6 | Time to current peak (TTP, from stimulus onset) at various pressures. (A, C,E) in Cav1.2 and (B,D,F) in Cav3.2 channels. (A,B) TTP measured in a single oocyte. (C,D) Pooled data of the channels. (E,F)

Normalized TTP: each curve is normalized to its own minimal value and
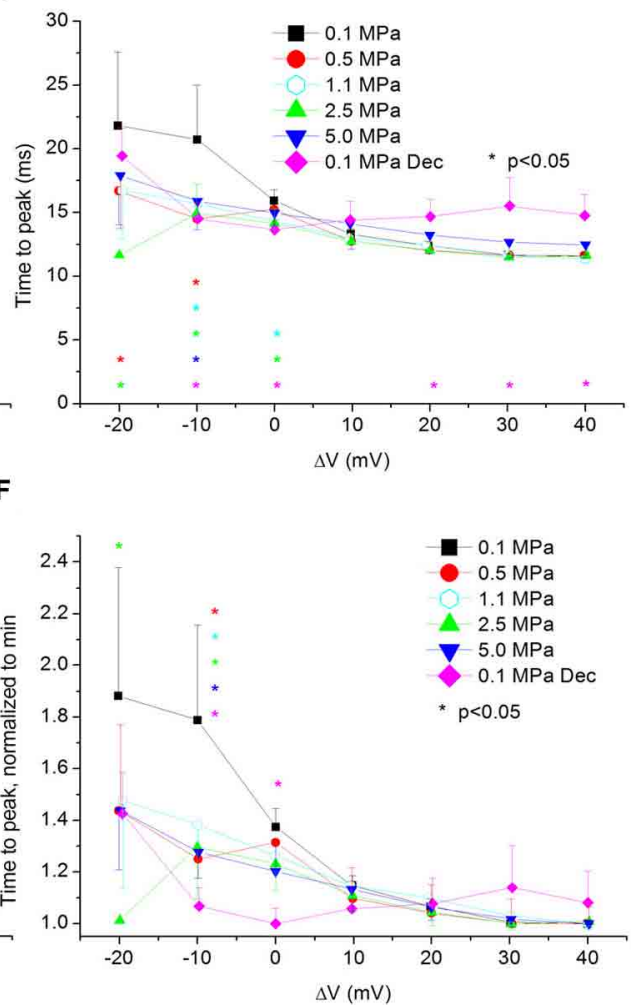

corresponds to its pertinent curve in (C,D). Pressures are color indicated. Statistical significance for each point on the curve is indicated by corresponding color asterisks. Holding potential is expressed as in Figure 2. Dec indicates decompression. depolarizations $(\Delta \mathrm{V} 10-40 \mathrm{mV})$ at HP did not change TDecay Fast, but after decompression its values were slightly smaller $(\Delta \mathrm{V} 30$ $40 \mathrm{mV}$ ). In the rest of the depolarizing range, decompression fully recovered TDecay Fast. For the $\mathrm{Ca}_{V} 3.2$, the ruling trend was a reduction of TDecay Fast at HP, mainly from $\mathrm{V}_{\text {Imax }}$ and above (Figure 8D), while decompression did not relieve this effect. Normalizing each curve to its own minimal value showed for the Cav1.2 channel a depression at 2.5 and $5.0 \mathrm{MPa}$, but not at $0.5 \mathrm{MPa}$ (Figure 8E), while decompression increased the nor-

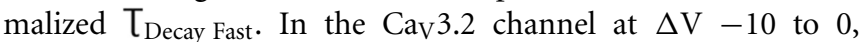
compression to 1.1 and $5.0 \mathrm{MPa}$ (but not to 0.5 and $2.5 \mathrm{MPa}$ ) increased the normalized $T_{\text {Decay Fast }}$ (Figure 8F), which remained elevated after decompression in this activity range.

$\Delta \mathrm{V}^{\ddagger}$ of fast decay inactivation at $\mathrm{V}_{\text {Imax }}$ was calculated to be -332 and $-55 \mathrm{ml} / \mathrm{mole}$ at $5.0 \mathrm{MPa}$ for $\mathrm{Ca}_{\mathrm{V}} 1.2$ and $\mathrm{Ca}_{\mathrm{V}} 3.2$, respectively. 

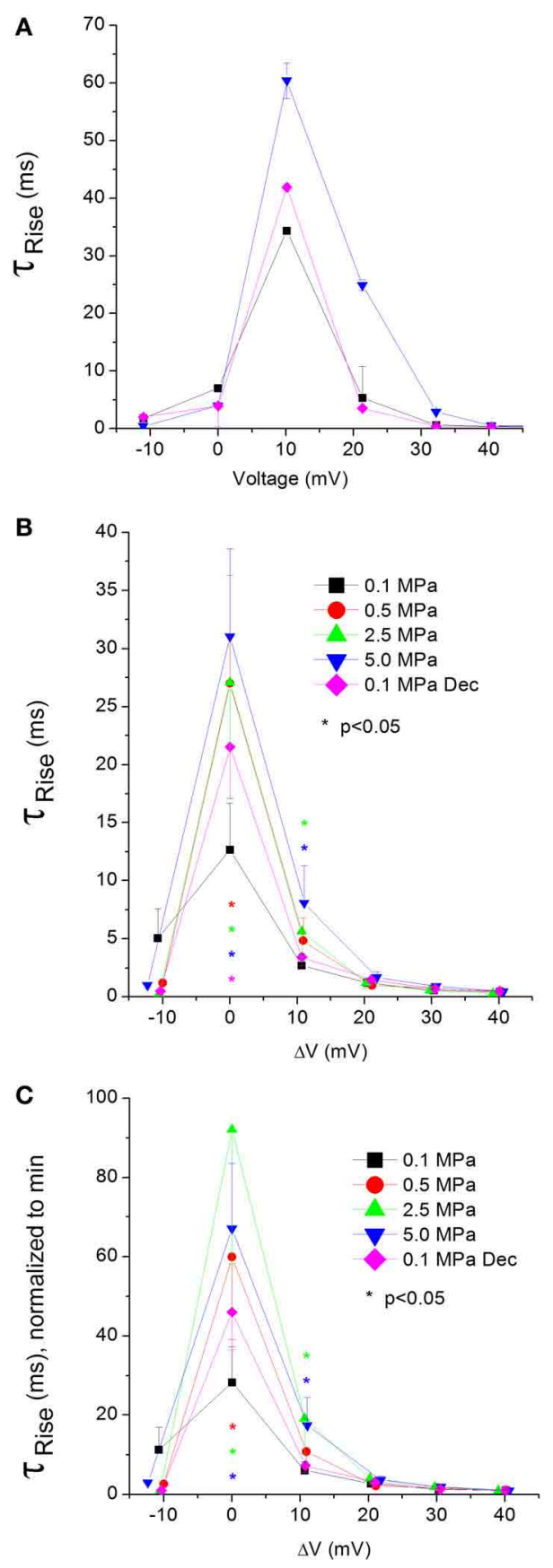

FIGURE 7 | Time constant of current activation ( $T_{\text {Rise }}$ ) in Cav 1.2 channel. (A) $T_{\text {Rise measured in a single oocyte. (B) Pooled data of } T_{\text {Rise }}}$ from 7 to 16 oocytes. (C) Normalized $T_{\text {Rise }}$ : each curve is normalized to its own minimal value and corresponds to its pertinent curve in (B). Pressures are color indicated. Statistical significance for each point on the curve is indicated by corresponding color asterisks. Holding potential is expressed as in Figure 2. Dec indicates decompression.

\section{CURRENTS SLOW TDECAY}

The slow $T_{\text {Decay }}$ ( $T_{\text {Decay Slow }}$ ) in both channels was increased by stronger depolarizations at $0.1 \mathrm{MPa}$ (Figures 9A,B).

For the Cav1.2 channel TDecay Slow does not seem to be sensitive to $\mathrm{HP}$, as no consistent significant difference was found in its values after compression or decompression (Figure 9C). For the $\mathrm{Ca}_{\mathrm{V}} 3.2$ channel TDecay Slow was shortened only by strong depolarization $(\Delta \mathrm{V} 30-40 \mathrm{mV})$ at HP, while decompression eliminated this effect (Figure 9D). The normalized curves of TDecay slow for both channels did not reveal a behavior different than that described above (Figures 9E,F).

$\Delta \mathrm{V}^{\ddagger}$ of slow decay inactivation at $\mathrm{V}_{\text {Imax }}$ was calculated to be -32 and $179 \mathrm{ml} / \mathrm{mole}$ at $5.0 \mathrm{MPa}$ for $\mathrm{Ca}_{V} 1.2$ and $\mathrm{Ca}_{V} 3.2$, respectively.

\section{CURRENTS TTAIL}

The tail current time constant ( $\mathrm{T}_{\text {Tail }}$ ), representing the kinetics of the channels' deactivation, was shortened by increasing depolarization in the $\mathrm{Ca}_{\mathrm{V}} 1.2$ channel (see example in Figure 10A). This trend persisted with the application of HP, but at 5.0 MPa TTail remained minimal throughout the activity range of the channel (Figure 10B). Strong depolarization $(\Delta \mathrm{V} 10-40 \mathrm{mV})$ at $\mathrm{HP}(0.5$ and 5.0, but not $2.5 \mathrm{MPa}$ ) shortened T Tail. The normalized curves of TTail stress the absence of a significant slope at $5.0 \mathrm{MPa}$ (Figure $10 \mathrm{C}$ ). $\Delta \mathrm{V}^{\ddagger}$ of deactivation for $\mathrm{Ca}_{\mathrm{V}} 1.2$ at $\mathrm{V}_{\text {Imax }}$ was calculated to be $-432 \mathrm{ml} / \mathrm{mole}$ at $5.0 \mathrm{MPa}$.

Unfortunately, the reciprocal artifact for the one interfering with measuring TRise in the $\mathrm{Ca}_{\mathrm{V}} 3.2$ channel also prevented an accurate measurement of $T_{\text {Tail }}$.

\section{DISCUSSION}

\section{ESTABLISHING THE METHODOLOGY}

The use of a truncated $\mathrm{K}^{+}$channel proved the stability of measurements in our setup in these unusually long oocyte experiments, which were necessary due to adiabatic temperature fluctuations. Furthermore, there was no indication of long-term $(1 \mathrm{~h})$ effects of the fluctuating adiabatic temperature on barium currents once control temperature was restored (Figure 3B), suggesting that it cannot account for the much greater pressureinduced changes in maximal currents. Due to the relatively quick response of the preparation (Figure 3A), and in comparison to previous studies (Grossman and Kendig, 1984), it is likely that the time course of recovery from temperature transients is no longer than a few minutes, and therefore at the time of current measurements, when the ambient temperature is within $0.5^{\circ} \mathrm{C}$ deviation from control value, the membrane does not exhibit properties of temperature a few degrees higher or lower.

Additional support for this assumption arises from experiments in lobster (Panulirus interruptus) bifurcating axon, which showed that 10-15 min were sufficient to allow the responses to recover to the original levels and remain stable (Grossman and Kendig, 1986).

In the present experiments, cooling back to control temperature after compression steps lasted $12-15 \mathrm{~min}$, with at least an additional 5-6 min required for verifying stability of currents. Thus, the total time of $17-21 \mathrm{~min}$ seems pertinent to allow the preparation to "relax" to its new pressure condition without temperature change interference. However, we cannot completely rule out the possibility that transient adiabatic temperature fluctuation contributes to the current change at pressure per se. In order to do so, conditions of compression need to allow a constant temperature during pressure changes, i.e., preventing or 

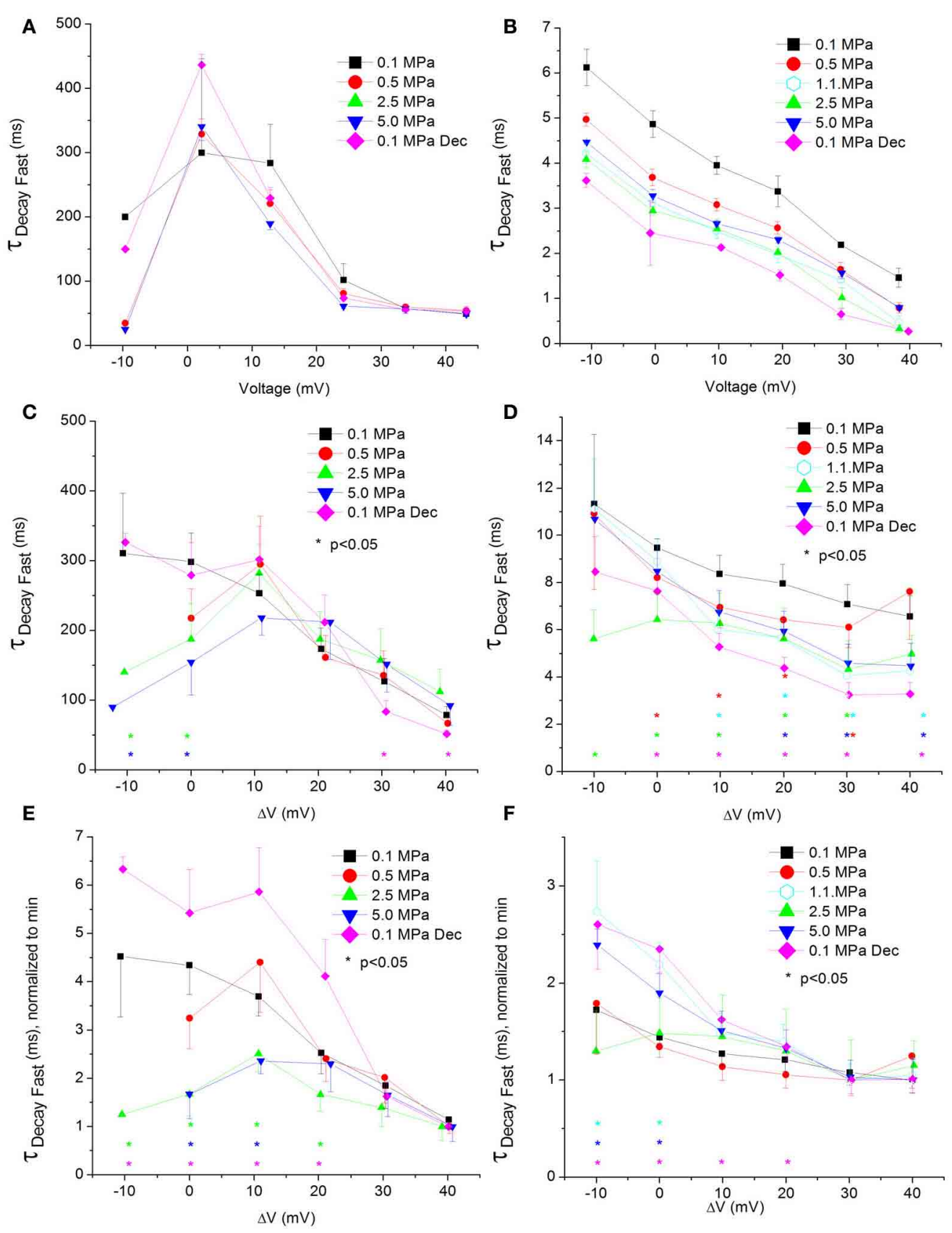

FIGURE 8 | Fast time constant of voltage- and time-dependent

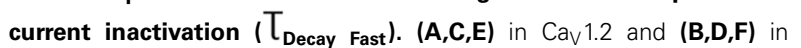
Cav3.2 channels. (A,B) $T_{\text {Decay Fast measured in a single oocyte. }}(\mathbf{C}, \mathbf{D})$ Pooled data of the channels. (E,F) Normalized $T_{\text {Decay Fast }}$ : each curve is normalized to its own minimal value and corresponds to its pertinent curve in $\mathbf{( C , D )}$. Pressures are color indicated. Statistical significance for each point on the curve is indicated by corresponding color asterisks. Holding potential is expressed as in Figure 2. Dec indicates decompression. minimizing adiabatic temperature fluctuations. Only liquid compression can achieve this stipulation to a high degree, but unfortunately cannot be employed in our current setting. Nevertheless, Schmalwasser et al. (1998) have managed to design and operate a hydrostatic (oil) pressure chamber, in which adiabatic temperature fluctuation in compressions steps of $10 \mathrm{MPa}$ was only $0.5^{\circ} \mathrm{C}$ or less, and demonstrated a reversible reduction of currents in the
Shaker potassium channel mutant Shaker BD6-46 T449K. These results show that high pressure induced its effects on the channel even when temperature fluctuation was minimized, suggesting that our results were not distorted by the small temperature change.

The use of the 9-AC blocker both in normobaric and HP conditions strongly suggested that the endogenous $\mathrm{Cl}_{\mathrm{Ca}}^{-}$currents are 

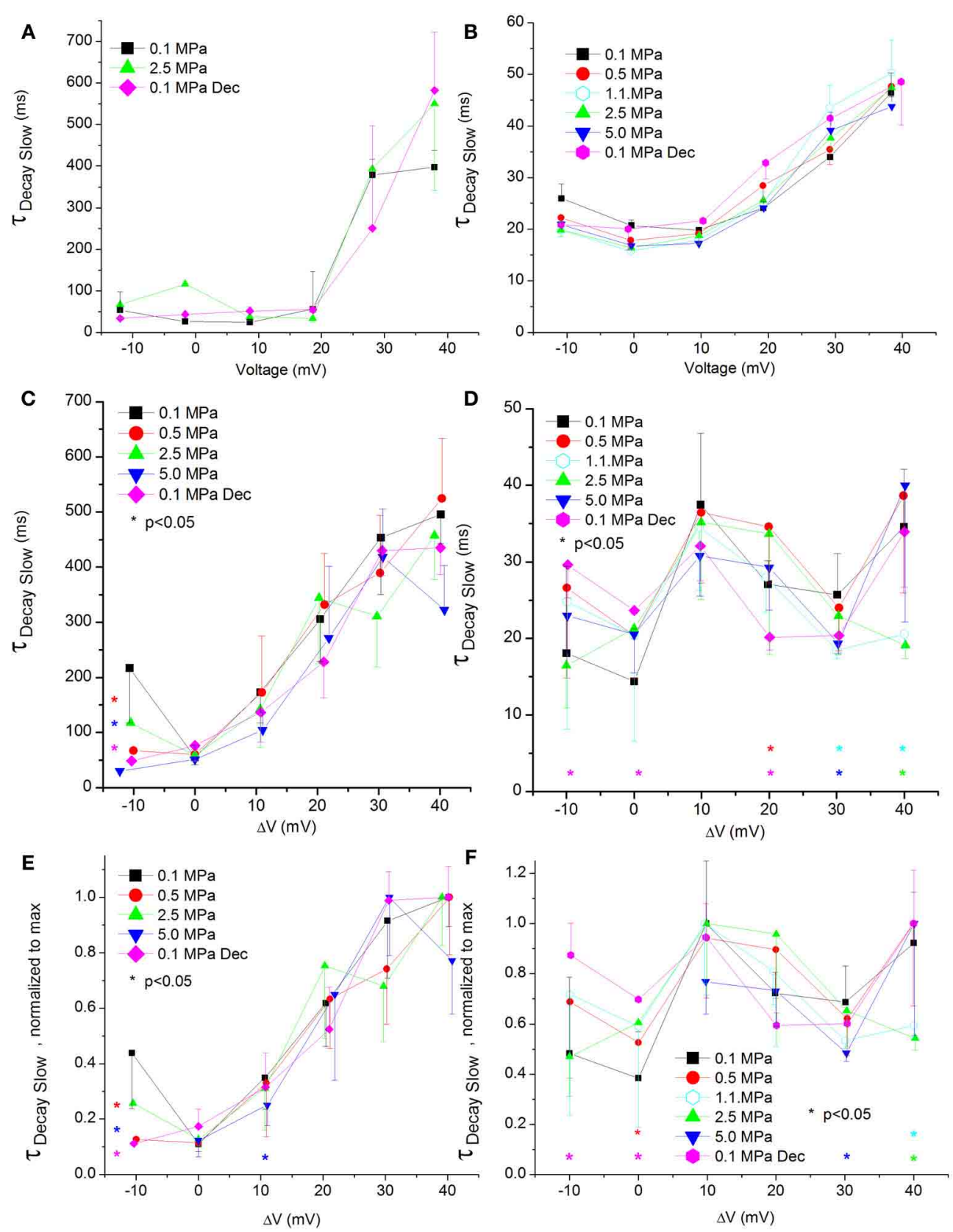

FIGURE 9 | Slow time constant of voltage- and time-dependent current inactivation $\left(T_{\text {Decay slow }}\right) .(\mathbf{A}, \mathbf{C}, \mathbf{E})$ in $C_{\text {av } 1.2}$ and $(\mathbf{B}, \mathbf{D}, \mathbf{F})$ in Cav3.2 channels. (A,B) $T_{\text {Decay slow measured in a single oocyte. }}(\mathbf{C}, \mathbf{D})$ Pooled data of the channels $T_{\text {Decay slow. }}(\mathbf{E}, \mathbf{F})$ Normalized $T_{\text {Decay slow: }}$

each curve is normalized to its own maximal value and corresponds to its pertinent curve in (C,D). Pressures are color indicated. Statistical significance for each point on the curve is indicated by corresponding color asterisks. Holding potential is expressed as in Figure 2. Dec indicates decompression.

not of significant importance in our experiments (Figures 3C,D). Furthermore, the use of $\mathrm{Ba}^{2+}$ as a charge carrier proved to be efficient, as currents were stronger and the $\mathrm{Ca}^{2+}$ inactivation was eliminated (Figure 3E) as expected (Lyford et al., 2002).

Taken together, these control experiments show that the changes demonstrated after compression are indeed pressure related.
The HP-induced depression demonstrated in the Cav 3.2 channel further strengthened our findings in the Cav 1.2 channel, ruling out the possibility of it being a setup-related artifact.

\section{CURRENTS' ACTIVATION}

\section{Currents' amplitude}

We show here, for the first time by direct measurement, that pressure effect can be selective: currents through Cav 1.2 are increased, 

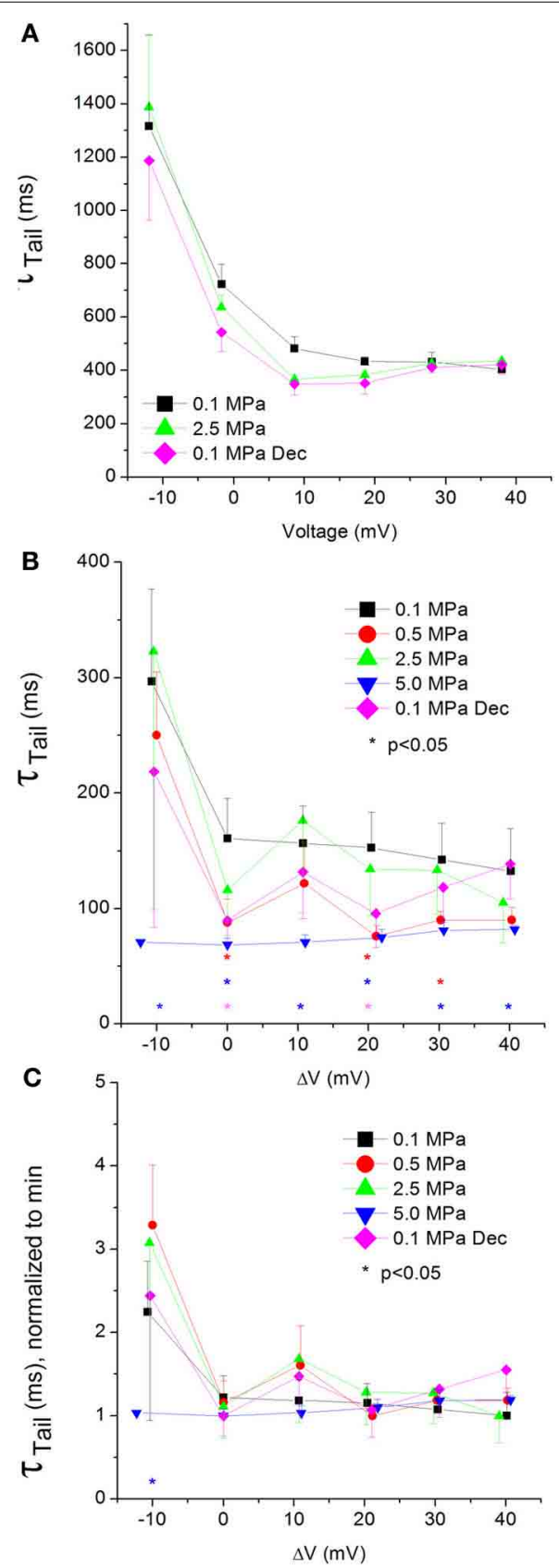

FIGURE 10 | Tail current time constant ( $\tau_{\text {Tail }}$ in Cav 1.2 channel. (A) $T_{\text {Tail }}$ measured in a single oocyte. (B) Pooled data of $T_{\text {Tail }}$ from 7 to 16 oocytes. Only 5.0 MPa has affected (reduced) $\tau_{\text {Tail }}$ throughout the channels' activity range. (C) Normalized $T_{\text {Tail }}$ : each curve is normalized to its own minimal value and corresponds to its pertinent curve in (B). Pressures are color indicated. Statistical significance for each point on the curve is indicated by corresponding color asterisks. Holding potential is expressed as in Figure 2. Dec indicates decompression.

whereas currents through the Cav3.2 channel are depressed, at HP. It is noteworthy that the $\mathrm{Ca}_{\mathrm{V}} 3.2$ is more sensitive to pressure changes than the $\mathrm{Ca}_{v} 1.2$ channel, as the HP effect is already saturated at 1.1 MPa. Furthermore, currents in the $\mathrm{Cav}_{\mathrm{v}} 1.2$ were partially recovered on return to atmospheric pressure, whereas in the $\mathrm{Ca}_{\mathrm{V}} 3.2$ currents did not recover. Although the $\mathrm{Ca}_{\mathrm{V}} 3.2$ channel is found in neuronal somata and much less in the nerve terminals, the findings demonstrate the possibility of selective pressure effects on other types of $\mathrm{Ca}^{2+}$ channels $(\mathrm{P} / \mathrm{Q}, \mathrm{N}, \mathrm{R})$ that are believed to be present at the presynaptic nerve terminals (Uchitel et al., 1992; Etzion and Grossman, 2000). Such a selectivity was already indirectly suggested in our experiments on frog motor nerve terminals (Aviner et al., 2013).

The effect on the Cav1.2 is apparently in contrast to previous reports that suggested reduction in $\mathrm{Ca}^{2+}$ influx through $\mathrm{Ca}_{V} 2.2$ (Grossman et al., 1991), and a lesser (Etzion and Grossman, 2000; Aviner et al., 2013) or no effect (Heinemann et al., 1987) in Ltype VDCC $\left(\mathrm{Ca}_{V} 1\right)$ at pressure. The $\mathrm{Ca}_{V} 3.2$ current reduction conforms to the above notion. However, in part of the studies (Grossman et al., 1991; Etzion and Grossman, 2000) Cav 1.2 involvement was excluded pharmacologically, while in others it was assumed absent based on information obtained from similar or identical preparations (Robitaille et al., 1990; French et al., 2002). In the chromaffin cells the channels were denoted as Cav 1 simply due to their similar behavior to these channels in neuronal cells, and have not been characterized pharmacologically. Lastly, the one change observed in $\mathrm{Ca}^{2+}$ currents in the bovine chromaffin cells was a slight increase at $40 \mathrm{MPa}$, which might support our finding of augmentation of currents in the $\mathrm{Ca}_{\mathrm{V}} 1.2$ (probably a different isoform) at lower pressure. Thus, the HP-induced increase of current in $\mathrm{Ca}_{V} 1.2$ could be specific and excludes other types of channel of the same family $\left(\mathrm{Ca}_{V} 1\right)$.

The augmentation of the currents in Cav1.2 channel at HP demonstrated here is reminiscent of another member of this protein superfamily behavior, the $\mathrm{K}^{+}$channels. The non-inactivating "delayed rectifier" $\mathrm{K}^{+}$channels pass greater steady-state currents at pressure in invertebrates such as squid (Henderson and Gilbert, 1975; Shrivastav et al., 1981; Conti et al., 1982a), snail (Harper et al., 1981), and lobster (Grossman and Kendig, 1984). Enhanced $\mathrm{K}^{+}$currents at pressure were also proposed as the basis for the firing patterns of $\mathrm{Ca}^{2+}$ APs in guinea pig Purkinje cells (Etzion and Grossman, 1999), and for slowing of the sinus-node pacemaker activity in various mammalian hearts (Ornhagen and Hogan, 1977). On the other hand, the reduction of currents in the $\mathrm{Ca}_{v} 3.2$ shown here is in agreement with other experiments concerned with an inactivating type of the $\mathrm{K}^{+}$channel, demonstrating a depression of currents at pressure in snail (Harper et al., 1981) and in mouse Shaker $\mathrm{B} \mathrm{K}^{+}$channels expressed in Xenopus oocytes (Meyer and Heinemann, 1997; Schmalwasser et al., 1998).

Previous studies in our laboratory in rat dentate gyrus corticohippocampal slices suggested that high pressure increases the transfer function between synaptic inputs and somatic spike generation by granule cells, despite the observed reduction of single field excitatory post-synaptic potential (fEPSP) amplitude and slope by nearly 50\% (Talpalar and Grossman, 2004). This suggests that high pressure depresses synaptic activity while increasing excitability in the neuronal dendrites but not in the axons. The Cav1.2 channels that were studied here are known to be present in the cell bodies and proximal dendrites of neurons in the dentate gyrus (Hell et al., 1993). It is suggested that pressure-potentiated $\mathrm{Ca}_{\mathrm{V}} 1.2$ currents in the dendrite may boost 
subthreshold synaptic potentials to generate APs. Such a dendritic hyperexcitability could explain the increased transfer function and is a good example of another way through which pressure selective effects on VDCC might impact neuronal networks, other than synaptic transmission. Such an increased transfer function mechanism may conform to the hyperexcitability manifested in HPNS.

It is interesting to note that the $\mathrm{Ca}_{\mathrm{V}} 1.2$ is also expressed in the cardiac muscle, and the $\mathrm{Ca}_{\mathrm{v}} 3.2$ in the cardiac Purkinje fibers. Both changes in the maximal current amplitude described here correlate with previous findings: an increase in the contractility force of isolated rat hearts (Ornhagen and Sigurdsson, 1981; Gennser and Ornhagen, 1989a) and a decrease in the contraction pace in rat (Gennser and Ornhagen, 1989b) and humans (Linnarsson et al., 1999; Kurita et al., 2002).

A positive ionotropic pressure effect at steady-state that was reported for skeletal and cardiac muscles was previously explained by increase of cytosolic $\mathrm{Ca}^{2+}$ that may occur due to inhibition of $\mathrm{Ca}^{2+}$ removal from the cytosol, into either cellular or extracellular compartments (Daniels and Grossman, 2003). Our study may offer a different or additional mechanism for these changes in inotropy.

The augmented $\mathrm{Ca}_{V} 1.2$ currents may increase neuronal dendritic excitability and therefore contribute to the generation of HPNS. The contribution to HPNS of the reduction of $\mathrm{Ca}_{V} 3.2$ currents is less obvious. These low threshold activated channels are especially involved in generating bursting behavior and rhythmic activity in pace-maker neurons in the reticular thalamic nucleus, thalamus, striatum, and cortex, where they are involved in controlling sleep, awareness, executive function, movement planning and modulation, and sensory inputs, respectively. We may speculate that the current reduction will slow this activity and impair these neuronal "clocks" function. This may interfere with time processing and coincidence detection as well as motor and sensory functions in a manner similar to HPNS signs and symptoms. A slower rhythm at HP was indeed found in humans, where EEG waves shifted from $\alpha$ to $\theta$ patterns (Rostain et al., 1997). The same study also demonstrated sleep disturbances that were more prominent during the beginning of the compression, subsided later, and were abolished at decompression, suggesting both transient and reversible HP effect, similar to the results shown in our experiments.

The amplitude of slow after-hyperpolarization (sAHP) in rat CA1 was reduced by HP (Southan and Wann, 1996). This reduction could be explained by a depression of the SK potassium channel, responsible for the sAHP. But since this channel is activated by the rise of $\left[\mathrm{Ca}^{2+}\right]_{i}$ during each $\mathrm{AP}$, it can also be pointing to a reduction in $\mathrm{Ca}^{2+}$ influx through VDCCs, e.g., Cav3.2, not only in the synaptic terminal but also along the axon and possibly in the soma and dendrites as well.

It is worth noting that our pressure effect on $\mathrm{Ca}_{v} 3.2$ is saturating at about $1.1 \mathrm{MPa}$. This is well correlated with the pressure experienced by professional divers in the depth of seawater in which they begin to complain of the HPNS signs and symptoms. Therefore, this might be an indication that the $\mathrm{Ca}_{\mathrm{V}} 3.2$ is also involved in the underlying mechanism of this phenomenon. It is postulated that the mild symptoms observed at lower pressures such as impaired cognitive capabilities and motor dexterity are the consequence of pacemaker malfunction as a result of reduction in $\mathrm{Ca}_{\mathrm{V}} 3.2$ maximal currents.

\section{Channels' conductance}

Overall, the calculated conductance behavior relative to the membrane potential (Figure 4) is in accordance with the I-V curves described in Figure 2. Although generally the HP effect for $\mathrm{Ca}_{\mathrm{V}} 1.2$ and $\mathrm{Ca}_{V} 3.2$ channels is opposite, at $\Delta \mathrm{V}-10 \mathrm{mV}$ both demonstrate an increase of conductance at HP (5.0 MPa, Figures 4C,D). The $\mathrm{Ca}_{V} 3.2$ normalized-to-max conductance curve better shows the channels' postulated tendency to shift to an open state at HP in membrane potentials just over the threshold. However, once depolarization is increased the maximal currents and the conductance are depressed by HP. If HP raises the probability to shift to an open state, why would the currents depress? A possible explanation could be a stronger and faster inactivation of the channel at HP throughout the channels' activity range. Indeed, an indication for that can be seen by a decrease in both $\mathrm{I}_{\text {end }} / \mathrm{I}_{\max }$ and TDecay Fast at HP (Figures 5D,F and 8D,F, respectively).

The fact that only compression to $0.5 \mathrm{MPa}$ caused a reduction in the normalized-to-max conductance curve above $\mathrm{V}_{\text {Imax }}$ in both channels (Figures 4E,F) may suggest a transient sensitivity of their "voltage sensor" to HP.

\section{Currents TTP and TRise}

Both TTP and TRise elongate at HP for the CaV1.2 channel, strongly suggesting a slower activation (Figures 6C, 7C, respectively). A similar HP effect was reported in previous studies on VDCCs in guinea pig single cerebellar Purkinje cells (probably $\mathrm{Ca}_{V}$ 2.1) (Etzion and Grossman, 1999) and frog motor nerve (possibly Cav2.2) (Aviner et al., 2013). The velocity of an AP was also reduced at HP after a transient increase (Grossman and Kendig, 1986).

On the other hand, TTP was shortened in a narrow voltage range $\left(-20 \mathrm{mV}\right.$ up to $\left.\mathrm{V}_{\mathrm{Imax}}\right)$ in the $\mathrm{Ca}_{\mathrm{V}} 3.2$ (Figure 6D), suggesting a faster activation of the channel at HP. Nevertheless, shortening of TTP may also point to a faster inactivation process, which will make the maximal current appear earlier. This indeed was found in the $\mathrm{Ca}_{V} 3.2$, where TDecay Fast has shortened at HP (Figure 8D). Unfortunately, the inability to measure TRise for $\mathrm{Ca}_{\mathrm{V}} 3.2$ in this case prevents distinguishing the two options. However, the opposite HP effect on TTP, conductance, and maximal currents for these channels, together with the fact that TDecay Fast was not significantly elongated for the Cav 1.2 at HP (Figure 8C) although TTP was increased, may indicate that for the Cav3.2 TRise may be shortened at HP.

\section{CURRENT INACTIVATION}

As expected for a fast inactivating channel, the $\mathrm{Ca}_{V} 3.2$ shows a lower value of $\mathrm{I}_{\mathrm{end}} / \mathrm{I}_{\max }$ (stronger inactivation) than the Cav 1.2 for any given membrane potential (Figures 5A-D). At $\mathrm{V}_{\text {Imax }}$ the $\mathrm{I}_{\text {end }} / \mathrm{I}_{\max }$ value has decreased for the $\mathrm{Ca}_{\mathrm{V}} 1.2$ at $\mathrm{HP}$, and the same happened for the $\mathrm{Ca}_{\mathrm{V}} 3.2$ at $\Delta \mathrm{V}-10$ to $-20 \mathrm{mV}$. This correlates well with smaller TDecay Fast (faster inactivation) in both channels in this voltage range at HP (Figures 8C,D). On the other 
hand, stronger depolarization $(\Delta \mathrm{V} 10-40 \mathrm{mV})$ at $\mathrm{HP}$ has led to weaker inactivation in the $\mathrm{Ca}_{V} 1.2$ but not in the $\mathrm{Ca}_{\mathrm{V}} 3.2$ channel (Figures 5C,D). These findings are not supported by the measured TDecay Fast in both channels in the same voltage range: it was not changed in the Cav1.2 and it was still reduced in the Cav3.2. For the latter it seems that since the inactivation has managed to reach its maximal values at the end of the $100 \mathrm{~ms}$ time window (end of depolarizing step), the faster TDecay Fast at HP has only facilitated the already strong inactivation and did not change its values. For the $\mathrm{Ca}_{V} 1.2$ channel the TDecay Fast averages are generally higher at HP for $\Delta \mathrm{V} 10$ and above, although not statistically significant, but probably enough to weaken the measured inactivation. A slower inactivation at $\mathrm{HP}$ was also reported in $\mathrm{Na}^{+}$ channel in bovine chromaffin cells (Heinemann et al., 1987), but not in the Helix snail (Harper et al., 1981).

The flatter normalized-to-minimum curve of inactivation in $\mathrm{Ca}_{\mathrm{V}} 1.2$ at $0.1 \mathrm{MPa}$ relative to $\mathrm{HP}$ curves (Figure 5E) and the linear behavior of TDecay Fast at $0.1 \mathrm{MPa}$ and after decompression as opposed to the behavior at HP (Figure 8C) both suggest that the molecular mechanism controlling the voltage-dependent inactivation is affected by HP.

Notwithstanding, no significant changes were observed in the TDecay Slow at HP in both channels, supporting the concept of different mechanisms for the fast and slow inactivation (Hering et al., 2000; Sokolov et al., 2000), which can also react differently to external treatment (Livneh et al., 2006). It was also demonstrated that the molecular structures responsible for these two types of inactivation are differently located in the VDCC's protein (Berjukow et al., 1999) and that the fast inactivation may act similarly to the "ball and chain" mechanism in the $\mathrm{K}^{+}$channel (Cens et al., 1999), while the slow inactivation seems to be at least partially dependent on the interaction between $\alpha_{1}$ and $\beta$ subunits (Sokolov et al., 2000). We suggest that the selective HP effect between the two channels' inactivation $\left(\mathrm{I}_{\text {end }} / \mathrm{I}_{\max }\right.$ and $\mathrm{TDecay}_{\text {De }}$ ) may arise from different conformational changes at HP, resulting from a different basic spatial organization of the channels, specifically their inactivation controlling regions.

\section{CURRENTS DEACTIVATION}

\section{Currents TTail}

Compression to 0.5 and $5.0 \mathrm{MPa}$, but not $2.5 \mathrm{MPa}$, shortened T Tail for $\mathrm{Ca}_{\mathrm{V}} 1.2$, implying a faster deactivation of the channel at HP (Figure 10B). The lack of consistency in the HP effect on TTail may suggest a transient effect caused by the initial compression $(0.5 \mathrm{MPa})$, and the inability of the deactivating mechanism to compensate for the higher HP (5.0 MPa).

The normalized curves show that in the $\mathrm{Ca}_{V} 1.2$ the reduction of $\mathrm{T}_{\text {Tail }}$ has saturated at $\mathrm{V}_{\text {Imax }}$ at normobaric and HP (Figure 10C). However, at $5.0 \mathrm{MPa}$ saturation was achieved already at $\Delta \mathrm{V}-10 \mathrm{mV}$, which may indicate that the closure of the channel is facilitated by high HP.

\section{SUMMARY}

HP affected the behavior of both $\mathrm{Ca}_{V} 1.2$ and $\mathrm{Ca}_{V} 3.2$, whether throughout their membrane potential activity range (maximal current, conductance, $\mathrm{T}_{\text {Tail }}$ at $5.0 \mathrm{MPa}$ ), or just at a confined voltage range ( $\mathrm{T}_{\text {Rise }}, \mathrm{TTP}$, inactivation, $\mathrm{T}_{\text {Decay Fast }}$ ). The HP effect on the two channels was generally opposite (maximal currents, conductance, TTP), but some kinetic traits shared the same HPinduced tendencies (inactivation at $\mathrm{V}_{\mathrm{Imax}}$, $\mathrm{T}_{\text {Decay Fast }}$ ). Some of the effects may indicate a transient nature (conductance and partially $\mathrm{T}_{\text {Tail }}$ ), while other suggested that the HP effect can be reversible (mostly for $\mathrm{Ca}_{V} 1.2$; TDecay Fast, TTail, and partially also maximal current and $\left.T_{\text {Rise }}\right)$. A summary of the major HP-induced findings is given in Table 1.

These changes in the response to depolarization, in both magnitude and kinetics, would undoubtedly influence these channels' functionality in neurons. Decrements in locomotor activity, myoclonus, tremors, changes in EEG, and sleep disorders, all part of the HPNS phenomenon, may be the manifestation of these HP-induced changes.

\section{GENERAL CONSIDERATIONS}

The effect of HP can be targeted either at the channel (and its subunits) or at any external modulator. Some of the characteristics examined in this study exhibited sensitivity (sometimes opposite) to HP that was also dependent on the membrane potential, suggesting that HP affects the channel itself. More specifically, HP may target the channels' "voltage sensor" and thus affect voltage-dependent mechanisms of activation, inactivation, and deactivation.

Several studies have demonstrated that replacing a section within a subunit (Tang et al., 1993; Zhang et al., 1994) or even a single amino acid (Bourinet et al., 1999; Hans et al., 1999) can dramatically change its reaction to depolarization. Furthermore, it was suggested that these changes are caused by different spatial organization of the subunits, influencing their interactions (Hering et al., 2000).

Similarly, the HP-induced effects demonstrated in this study may indicate that the conformational changes involved in the channels' activity are facilitated (e.g., activation in the Cav1.2, fast inactivation in the $\mathrm{Ca}_{\mathrm{V}} 3.2$ ) or opposed (e.g., activation in the $\mathrm{Ca}_{\mathrm{V}} 3.2$, rate of activation in the $\left.\mathrm{Ca}_{\mathrm{V}} 1.2\right)$ by an elevated ambient pressure. Indeed, this notion is supported by the calculated activation volumes corresponding to these processes, probably affecting the total ionic flux through the channels at HP. Furthermore, even the basic (i.e., not activated) spatial organization of the subunits and their interactions may be altered by the

Table 1 | General qualitative effect of HP found in our study on channel characteristics.

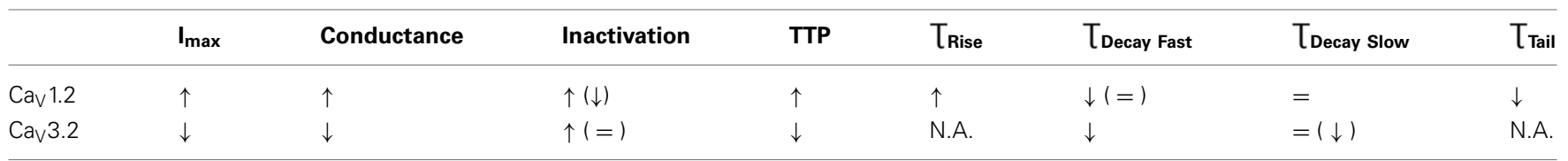

$\uparrow$, increase; $\downarrow$, decrease; =, no change; (), stronger depolarization. 
HP application (e.g., a segment within S4 transmembrane region, holding the positively charged amino acids sequence that serve as a voltage sensor), thus leading to the HP sensitivity shown here. For example, the human and rat glycine receptor affinity to its ligand was reduced at HP (Roberts et al., 1996). The reduced activity of this inhibitory mechanism may explain the tendency to hyperexcitability upon exposure to HP (HPNS manifestations). A genetic sequencing of the receptor demonstrated a few amino acid switches between the mammals mentioned above and the Pilot whale, one of them in the ligand binding site from the non-polar cysteine (human and rat) to the polar arginine $(\mathrm{C} 41 \mathrm{R})$. This switch may protect the whale from hyperexcitability at HP and provide it with the ability to dive to extreme depths.

It can therefore be postulated that performing HP experiments on a specific VDCC with altered subunits or a VDCC chimera might further elucidate the HP targeted site. Preliminary results from experiments on the NMDA receptor at HP may suggest that even changes in the extracellular $\mathrm{N}$ terminal domain can influence the magnitude and direction of the pressure effect (Mor et al., 2012).

\section{CONCLUSIONS}

(a) HP Modulation of various VDCCs is part of HPNS mechanisms and may explain some of its signs and symptoms.

(b) HP effects could be quite selective for the type of channel and/or various mechanisms underlying the channels' activity.

(c) HP effects on the channels' kinetics should be extensively studied in order to reveal small functional differences under HP conditions.

(d) Our study emphasizes the importance of pressure modulation of the membrane potential "sensor," which may determine the extent of pressure effects on the channels.

\section{REFERENCES}

Abraini, J. H. (1997). Inert gas and raised pressure: evidence that motor decrements are due to pressure per se and cognitive decrements due to narcotic action. Pflugers Arch. 433, 788-791. doi: 10.1007/s004240050346

Allen, B. W., Demchenko, I. T., and Piantadosi, C. A. (2009). Two faces of nitric oxide: implications for cellular mechanisms of oxygen toxicity. J. Appl. Physiol. 106, 662-667. doi: 10.1152/japplphysiol.91109.2008

Ashford, M. L., MacDonald, A. G., and Wann, K. T. (1982). The effects of hydrostatic pressure on the spontaneous release of transmitter at the frog neuromuscular junction. J. Physiol. 333, 531-543.

Aviner, B., Gnatek, Y., Gradwohl, G., and Grossman, Y. (2010). Hyperbaric pressure effects on voltage-dependent $\mathrm{Ca}^{+2}$ channels: relevance to HPNS. Undersea Hyperb. Med. 37, 245-258.

Aviner, B., Gradwohl, G., Moore, H. J., and Grossman, Y. (2013). Modulation of presynaptic $\mathrm{Ca}^{2+}$ currents in frog motor nerve terminals by high pressure. Eur. J. Neurosci. 38, 2716-2729. doi: 10.1111/ejn.12267

Bennett, P. B. (1997). "Inert gas narcosis and high pressure nervous syndrome," in Bove and Davis' Diving Medicine, eds A. A. Bove and J. C. Davis (Philadelphia, PA: Saunders), 117-130.

Berjukow, S., Gapp, F., Aczel, S., Sinnegger, M. J., Mitterdorfer, J., Glossmann, H., et al. (1999). Sequence differences between Alpha 1c and Alpha 1s $\mathrm{Ca}^{2+}$ channel subunits reveal structural determinants of a guarded and modulated benzothiazepine receptor. J. Biol. Chem. 274, 6154-6160. doi: 10.1074/jbc.274. 10.6154

Boton, R., Dascal, N., Gillo, B., and Lass, Y. (1989). Two calcium-activated chloride conductances in xenopus laevis oocytes permeabilized with the ionophore A23187. J. Physiol. 408, 511-534.
Bourinet, E., Soong, T. W., Sutton, K., Slaymaker, S., Mathews, E., Monteil, A., et al. (1999). Splicing of alpha la subunit gene generates phenotypic variants of Pand Q-type calcium channels. Nat. Neurosci. 2, 407-415. doi: 10.1038/8070

Campenot, R. B. (1975). The effects of high hydrostatic pressure on transmission at the crustacean neuromuscular junction. Comp. Biochem. Physiol. B 52, 133-140. doi: 10.1016/0305-0491(75)90128-5

Catterall, W. A. (2000). Structure and regulation of voltage-gated $\mathrm{Ca}^{2+}$ channels. Annu. Rev. Cell Dev. Biol. 16: 521-555. doi: 10.1146/annurev.cellbio.16.1.521

Cens, T., Restituito, S., Galas, S., and Charnet, P. (1999). Voltage and Calcium Use the Same Molecular Determinants to Inactivate Calcium channels. J. Biol. Chem. 274, 5483-5490. doi: 10.1074/jbc.274.9.5483

Conti, F., Fioravanti, R., Segal, J. R., and Stuhmer, W. (1982a). Pressure dependence of the potassium currents of squid giant axon. J. Membr. Biol. 69, 35-40. doi: 10.1007/BF01871239

Conti, F., Fioravanti, R., Segal, J. R., and Stuhmer, W. (1982b). Pressure dependence of the sodium currents of squid giant axon. J. Membr. Biol. 69, 23-34. doi: $10.1007 / \mathrm{BF} 01871238$

Daniels, S., and Grossman, Y. (2003). "Biological effects of pressure," in Bennett and Elliott's Physiology and Medicine of Diving, 5th Edn, eds A. O. Brubakk and T. S. Neuman (London: Saunders), 265-299.

Darbin, O., Risso, J. J., and Rostain, J. C. (2000). High pressure enhanced nmda activity in the striatum and the globus pallidus: relationships with myoclonia and locomotor and motor activity in rat. Brain Res. 852, 62-67. doi: 10.1016/S0006-8993(99)02195-2

Dean, J. B., Mulkey, D. K., Garcia, A. J. III., Putnam, R. W., and Henderson, R. A. I. I. I. (2003). Neuronal sensitivity to hyperoxia, hypercapnia, and inert gases at hyperbaric pressures. J. Appl. Physiol. 95, 883-909. doi: 10.1152/japplphysiol.00920.2002

Ertel, E. A., Campbell, K. P., Harpold, M. M., Hofmann, F., Mori, Y., Perez-Reyes, E., et al. (2000). Nomenclature of voltage-gated calcium channels. Neuron 25, 533-535. doi: 10.1016/S0896-6273(00)81057-0

Etzion, Y., Mor, A., and Grossman, Y. (2008). Differential modulation of cerebellar climbing fiber and parallel fiber synaptic responses at high pressure. J. Appl. Physiol. 106, 729-736. doi: 10.1152/japplphysiol.90853.2008

Etzion, Y., and Grossman, Y. (1999). Spontaneous $\mathrm{Na}^{+}$and $\mathrm{Ca}^{2+}$ spike firing of cerebellar purkinje neurons at high pressure. Pflugers Arch. 437, 276-284. doi: $10.1007 / \mathrm{s} 004240050780$

Etzion, Y., and Grossman, Y. (2000). Pressure-induced depression of synaptic transmission in the cerebellar parallel fibre synapse involves suppression of presynaptic N-Type $\mathrm{Ca}^{2+}$ channels. Eur. J. Neurosci. 12, 4007-4016. doi: 10.1046/j.1460-9568.2000.00303.x

French, L. B., Lanning, C. C., and Harris-Warrick, R. M. (2002). The localization of two voltage-gated calcium channels in the pyloric network of the lobster stomatogastric ganglion. Neuroscience 112, 217-232. doi: 10.1016/S03064522(01)00621-2

Gennser, M., and Ornhagen, H. C. (1989a). Effects of hydrostatic pressure and inert gases on twitch tension. Undersea Biomed. Res. 16, 415-426.

Gennser, M., and Ornhagen, H. C. (1989b). Effects of hydrostatic pressure, H2, N2, and $\mathrm{He}$, on beating frequency of rat atria. Undersea Biomed. Res. 16, 153-164.

Gilman, S. C., Colton, J. S., and Dutka, A. J. (1987). Effect of pressure on the release of radioactive glycine and gamma-aminobutyric acid from spinal cord synaptosomes. J. Neurochem. 49, 1571-1578. doi: 10.1111/j.1471-4159.1987.tb01029.x

Gilman, S. C., Kumaroo, K. K., and Hallenbeck, J. M. (1986). Effects of pressure on uptake and release of calcium by brain synaptosomes. J. Appl. Physiol. 60, 1446-1450.

Golan, H., and Grossman, Y. (1992). Synaptic transmission at high pressure: effects of $\left[\mathrm{Ca}^{2+}\right]_{O}$. Comp. Biochem. Physiol. Comp. Physiol. 103, 113-118. doi: 10.1016/0300-9629(92)90249-P

Golan, H., Moore, H. J., and Grossman, Y. (1994). Quantal analysis of presynaptic inhibition, low $\left[\mathrm{Ca}^{2+}\right] 0$, and high pressure interactions at crustacean excitatory synapses. Synapse 18, 328-336. doi: 10.1002/syn.890180408

Grossman, Y., Colton, J. S., and Gilman, S. C. (1991). Interaction of Ca-channel blockers and high pressure at the crustacean neuromuscular junction. Neurosci. Lett. 125, 53-56. doi: 10.1016/0304-3940(91)90129-H

Grossman, Y., and Kendig, J. J. (1984). Pressure and temperature: time-dependent modulation of membrane properties in a bifurcating axon. J. Neurophysiol. 52, 693-708.

Grossman, Y., and Kendig, J. J. (1986). Pressure and temperature modulation of conduction in a bifurcating axon. Undersea Biomed. Res. 13, 45-61. 
Grossman, Y., and Kendig, J. J. (1988). Synaptic integrative properties at hyperbaric pressure. J. Neurophysiol. 60, 1497-1512.

Grossman, Y., and Kendig, J. J. (1990). Evidence for reduced presynaptic $\mathrm{Ca}^{2+}$ entry in a lobster neuromuscular junction at high pressure. J. Physiol. 420, 355-364.

Halsey, M. J. (1982). Effects of high pressure on the central nervous system. Physiol. Rev. 62, 1341-1377.

Hans, M., Urrutia, A., Deal, C., Brust, P. F., Stauderman, K., Ellis, S. B., et al. (1999). Structural elements in domain iv that influence biophysical and pharmacological properties of human alphala-containing high-voltage-activated calcium channels. Biophys. J. 76, 1384-1400. doi: 10.1016/S0006-3495(99)77300-5

Harper, A. A., Macdonald, A. G., and Wann, K. T. (1981). The action of high hydrostatic pressure on the membrane currents of helix neurones. J. Physiol. 311, 325-339.

Heidelberger, R., Zhou, Z.-Y., and Matthews, G. (2002). Multiple components of membrane retrieval in synaptic terminals revealed by changes in hydrostatic pressure. J. Neurophysiol. 88, 2509-2517. doi: 10.1152/jn.00267.2002

Heinemann, S. H., Conti, F., Stuhmer, W., and Neher, E. (1987). Effects of hydrostatic pressure on membrane processes. Sodium channels, Calcium channels, and Exocytosis. J. Gen. Physiol. 90, 765-778. doi: 10.1085/jgp.90.6.765

Hell, J. W., Westenbroek, R. E., Warner, C., Ahlijanian, M. K., Prystay, W., Gilbert, M. M., et al. (1993). Identification and differential subcellular localization of the neuronal class C and Class D L-Type calcium channel alpha 1 subunits. J. Cell Biol. 123, 949-962. doi: 10.1083/jcb.123.4.949

Henderson, J. V., and Gilbert, D. L. (1975). Slowing of ionic currents in the voltage-clamped squid axon by helium pressure. Nature 258, 351-352. doi: $10.1038 / 258351 \mathrm{a} 0$

Hering, S., Berjukow, S., Sokolov, S., Marksteiner, R., Weiss, R. G., Kraus, R., et al. (2000). Molecular determinants of inactivation in voltage-gated $\mathrm{Ca}^{2+}$ channels. J. Physiol. 528, 237-249. doi: 10.1111/j.1469-7793.2000.t01-1-00237.x

Kurita, A., Nagayoshi, H., Okamoto, Y., Takase, B., Ishizuka, T., and Oiwa, H. (2002). Effects of severe hyperbaric pressure on autonomic nerve functions. Mil. Med. 167, 934-938.

Linnarsson, D., Ostlund, A., Lind, F., and Hesser, C. M. (1999). Hyperbaric bradycardia and hypoventilation in exercising men: effects of ambient pressure and breathing gas. J. Appl. Physiol. 87, 1428-1432.

Livneh, A., Cohen, R., and Atlas, D. (2006). A novel molecular inactivation determinant of voltage-gated Cav1.2 L-Type $\mathrm{Ca}^{2+}$ channel. Neuroscience 139, 1275-1287. doi: 10.1016/j.neuroscience.2006.01.028

Logue, P. E., Schmitt, F. A., Rogers, H. E., and Strong, G. B. (1986). Cognitive and emotional changes during a simulated 686-M deep dive. Undersea Biomed. Res. 13, 225-235.

Lyford, G. L., Strege, P. R., Shepard, A., Ou, Y., Ermilov, L., Miller, S. M., et al. (2002). Alpha 1c (Cav1.2) L-Type calcium channel mediates mechanosensitive calcium regulation. Am. J. Physiol. Cell Physiol. 283, C1001-C1008. doi: 10.1152/ajpcell.00140.2002

Meir, A., Ginsburg, S., Butkevich, A., Kachalsky, S. G., Kaiserman, I., Ahdut, R., et al. (1999). Ion channels in presynaptic nerve terminals and control of transmitter release. Physiol. Rev. 79, 1019-1088.

Meyer, R., and Heinemann, S. H. (1997). Temperature and pressure dependence of shaker $\mathrm{K}^{+}$Channel N- and C-Type inactivation. Eur. Biophys. J. 26, 433-445. doi: $10.1007 /$ s002490050098

Miledi, R., and Parker, I. (1984). Chloride current induced by injection of calcium into xenopus oocytes. J. Physiol. 357, 173-183.

Mor, A., Kuttner, Y. Y., Levy, S., Mor, M., Hollmann, M., and Grossman, Y. (2012). Pressure-selective modulation of nmda receptor subtypes may reflect 3d structural differences. Front. Cell Neurosci. 6:37. doi: 10.3389/fncel.2012. 00037

Ornhagen, H. C., and Hogan, P. M. (1977). Hydrostatic pressure and mammalian cardiac-pacemaker function. Undersea Biomed. Res. 4, 347-358.

Ornhagen, H. C., and Sigurdsson, S. B. (1981). Effects of high hydrostatic pressure on rat atrial muscle. Undersea Biomed. Res. 8, 113-120.

Otter, T., and Salmon, E. D. (1985). Pressure-Induced changes in $\mathrm{Ca}^{2+}$-channel excitability in paramecium. J. Exp. Biol. 117, 29-43.

Overman, W. H., Brauer, R. W., and Burke, E. R. (1989). Failure to find residual memory deficits in monkeys after repeated Hpns. Undersea Biomed. Res. 16, 115-127.

Parmentier, J. L., Shrivastav, B. B., and Bennett, P. B. (1981). Hydrostatic pressure reduces synaptic efficiency by inhibiting transmitter release. Undersea Biomed. Res. 8, 175-183.
Roberts, R. J., Shelton, C. J., Daniels, S., and Smith, E. B. (1996). Glycine activation of human homomeric alpha 1 glycine receptors is sensitive to pressure in the range of the high pressure nervous syndrome. Neurosci. Lett. 208, 125-128. doi: 10.1016/0304-3940(96)12550-7

Robitaille, R., Adler, E. M., and Charlton, M. P. (1990). Strategic location of calcium channels at transmitter release sites of frog neuromuscular synapses. Neuron 5 , 773-779. doi: 10.1016/0896-6273(90)90336-E

Rostain, J. C., Gardette-Chauffour, M. C., and Naquet, R. (1997). Eeg and sleep disturbances during dives at $450 \mathrm{msw}$ in helium-nitrogen-oxygen mixture. J. Appl. Physiol. 83, 575-582.

Schleifstein-Attias, D., Tarasiuk, A., and Grossman, Y. (1994). "High pressure effects on modulation of mammalian spinal monosynaptic reflex," in Basic and Applied High Pressure Biology, eds P. B. Bennett and R. E. Marquis (Rochester, NY: Rochester University Press), 193-199.

Schmalwasser, H., Neef, A., Elliott, A. A., and Heinemann, S. H. (1998). Twoelectrode voltage clamp of xenopus oocytes under high hydrostatic pressure. J. Neurosci. Methods 81, 1-7. doi: 10.1016/S0165-0270(98)00030-2

Shelton, C. J., Doyle, M. G., Price, D. J., Daniels, S., and Smith, E. B. (1993). The effect of high pressure on glycine- and kainate-sensitive receptor channels expressed in xenopus oocytes. Proc. Biol. Sci. 254, 131-137. doi: 10.1098/rspb.1993.0137

Shrivastav, B. B., Parmentier, J. L., and Bennett, P. B. (1981). "A quantitative description of pressure-induced alterations in ionic channels of the squid giant axon," in 7th Symposium on Underwater Physiology, Undersea Society Inc. (Athens), 611-619.

Sokolov, S., Weiss, R. G., Timin, E. N., and Hering, S. (2000). Modulation of slow inactivation in class a $\mathrm{Ca}^{2+}$ channels by $\{$ Beta $\}$-subunits. J. Physiol. 527, 445-454. doi: 10.1111/j.1469-7793.2000.t01-1-00445.x

Southan, A. P., and Wann, K. T. (1996). Effects of high helium pressure on intracellular and field potential responses in the Cal region of the in vitro rat hippocampus. Eur. J. Neurosci. 8, 2571-2581. doi: 10.1111/j.1460-9568.1996. tb01551.x

Steevens, C. C., Russell, K. L., Knafelc, M. E., Smith, P. F., Hopkins, E. W., and Clark, J. B. (1999). Noise-induced neurologic disturbances in divers exposed to intense water-borne sound: two case reports. Undersea Hyperb. Med. 26, 261-265.

Talpalar, A. E., Giugliano, M., and Grossman, Y. (2010). Enduring medial perforant path short-term synaptic depression at high pressure. Front. Cell Neurosci. 4:128. doi: $10.3389 /$ fncel. 2010.00128

Talpalar, A. E., and Grossman, Y. (2003). Modulation of rat corticohippocampal synaptic activity by high pressure and extracellular calcium: single and frequency responses. J. Neurophysiol. 90, 2106-2114. doi: 10.1152/jn. 00894.2002

Talpalar, A. E., and Grossman, Y. (2004). Enhanced excitability compensates for high-pressure-induced depression of cortical inputs to the hippocampus. J. Neurophysiol. 92, 3309-3319. doi: 10.1152/jn.00178.2004

Talpalar, A. E., and Grossman, Y. (2006). CNS manifestations of HPNS: revisited. Undersea Hyperb. Med. 33, 205-210.

Tang, S., Yatani, A., Bahinski, A., Mori, Y., and Schwartz, A. (1993). Molecular localization of regions in the l-type calcium channel critical for dihydropyridine action. Neuron 11, 1013-1021. doi: 10.1016/0896-6273(93)90215-D

Tarasiuk, A., and Grossman, Y. (1990). Pressure-induced tremor-associated activity in ventral roots in isolated spinal cord of newborn rats. Undersea Biomed. Res. $17,287-296$.

Tsien, R. W., Hess, P., McCleskey, E. W., and Rosenberg, R. L. (1987). Calcium channels: mechanisms of selectivity, permeation, and block. Annu. Rev. Biophys. Biophys. Chem. 16, 265-290. doi: 10.1146/annurev.bb.16.060187. 001405

Uchitel, O. D., Protti, D. A., Sanchez, V., Cherksey, B. D., Sugimori, M., and Llinas, R. (1992). P-type voltage-dependent calcium channel mediates presynaptic calcium influx and transmitter release in mammalian synapses. Proc. Natl. Acad. Sci. U.S.A. 89, 3330-3333. doi: 10.1073/pnas.89.8.3330

Vaernes, R. J., Bergan, T., and Warncke, M. (1988). Hpns effects among 18 divers during compression to $360 \mathrm{Msw}$ on heliox. Undersea Biomed. Res. 15 241-255.

Vogel, S. S., Smith, R. M., Baibakov, B., Ikebuchi, Y., and Lambert, N. A. (1999). Calcium Influx is required for endocytotic membrane retrieval. Proc. Natl. Acad. Sci. U.S.A. 96, 5019-5024. doi: 10.1073/pnas.96.9.5019

Wu, X. S., McNeil, B. D., Xu, J., Fan, J., Xue, L., Melicoff, E., et al. (2009). $\mathrm{Ca}(2+)$ and calmodulin initiate all forms of endocytosis during 
depolarization at a nerve terminal. Nat. Neurosci. 12, 1003-1010. doi: 10.1038/ nn. 2355

Zhang, J. F., Ellinor, P. T., Aldrich, R. W., and Tsien, R. W. (1994). Molecular determinants of voltage-dependent inactivation in calcium channels. Nature 372, 97-100. doi: 10.1038/372097a0

Zilberberg, N., Ilan, N., Gonzalez-Colaso, R., and Goldstein, S. A. N. (2000). Opening and closing of kcnko potassium leak channels is tightly regulated. J. Gen. Physiol. 116, 721-734. doi: 10.1085/jgp.116.5.721

Conflict of Interest Statement: The authors declare that the research was conducted in the absence of any commercial or financial relationships that could be construed as a potential conflict of interest.
Received: 11 September 2013; accepted: 30 April 2014; published online: 27 May 2014 Citation: Aviner B, Gradwohl G, Mor Aviner M, Levy S and Grossman Y (2014) Selective modulation of cellular voltage-dependent calcium channels by hyperbaric pressure-a suggested HPNS partial mechanism. Front. Cell. Neurosci. 8:136. doi: 10.3389/fncel.2014.00136

This article was submitted to the journal Frontiers in Cellular Neuroscience.

Copyright (c) 2014 Aviner, Gradwohl, Mor Aviner, Levy and Grossman. This is an open-access article distributed under the terms of the Creative Commons Attribution License (CC BY). The use, distribution or reproduction in other forums is permitted, provided the original author(s) or licensor are credited and that the original publication in this journal is cited, in accordance with accepted academic practice. No use distribution or reproduction is permitted which does not comply with these terms. 